\title{
Types of drug delivery system slide share of protactinium nanoparticles in human gum cancer cells, tissues and tumors treatment under synchrotron radiation
}

\author{
Alireza Heidari ${ }^{1,2 *}$, Katrina Schmitt ${ }^{1}$, Maria Henderson ${ }^{1}$ and Elizabeth Besana ${ }^{1}$ \\ ${ }^{1}$ Faculty of Chemistry, California South University, 14731 Comet St. Irvine, CA 92604, USA \\ ${ }^{2}$ American International Standards Institute, Irvine, CA 3800, USA
}

\begin{abstract}
In the current study, thermoplasmonic characteristics of Protactinium nanoparticles with spherical, core-shell and rod shapes are investigated. In order to investigate these characteristics, interaction of synchrotron radiation emission as a function of the beam energy and Protactinium nanoparticles were simulated using 3D finite element method. Firstly, absorption and extinction cross sections were calculated. Then, increases in temperature due to synchrotron radiation emission as a function of the beam energy absorption were calculated in Protactinium nanoparticles by solving heat equation. The obtained results show that Protactinium nanorods are more appropriate option for using in optothermal human cancer cells, tissues and tumors treatment method.
\end{abstract}

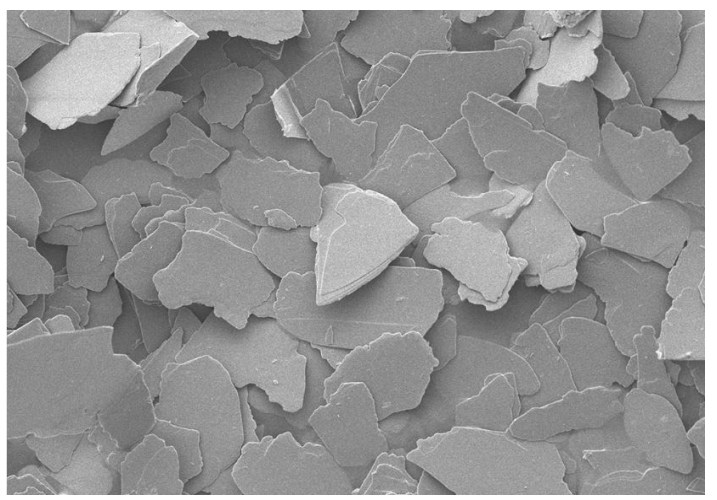

Scanning Electron Microscope (SEM) image of Protactinium nanoparticles with 50000x zoom.

\section{Introduction}

In recent decade, metallic nanoparticles have been widely interested due to their interesting optical characteristics [1-8]. Resonances of surface Plasmon in these nanoparticles lead to increase in synchrotron radiation emission as a function of the beam energy scattering and absorption in related frequency $[9,10]$. Synchrotron radiation emission as a function of the beam energy absorption and induced produced heat in nanoparticles has been considered as a side effect in plasmonic applications for a long time [11-15]. Recently, scientists find that thermoplasmonic characteristic can be used for various optothermal applications in cancer, nanoflows and photonic [16-22]. In optothermal human cancer cells, tissues and tumors treatment, the descendent laser light stimulate resonance of surface Plasmon of metallic nanoparticles and as a result of this process, the absorbed energy of descendent light converse to heat in nanoparticles [23-25]. The produced heat devastates tumor tissue adjacent to nanoparticles without any hurt to sound tissues [26,27]. Regarding the simplicity of ligands connection to Protactinium nanoparticles for targeting cancer cells, these nanoparticles are more appropriate to use in optothermal human cancer cells, tissues and tumors treatment [28-74]. In the current paper, thermoplasmonic characteristics of spherical, core-shell and rod Protactinium nanoparticles are investigated.

${ }^{*}$ Correspondence to: Alireza Heidari, Faculty of Chemistry, California South University, 14731 Comet St. Irvine, CA 92604; American International Standards Institute, Irvine, CA 3800, USA, E-mail: Scholar.Researcher.Scientist@gmail. com; Alireza.Heidari@calsu.us; Central@aisi-usa.org

Key words: protactinium nanoparticles, scanning electron microscope (SEM), $3 d$ finite element method (FEM), heat transfer equation, optothermal, heat distribution, thermoplasmonic, protactinium nanorods, human gum cancer cells, tissues and tumors treatment, simulation, synchrotron radiation, emission, function, beam energy

Received: December 05, 2019; Accepted: January 15, 2020; Published: January 19,2020 

radiation

\section{Heat generation in synchrotron radiation emission as a function of the beam energy-protactinium nanoparticles interaction}

When Protactinium nanoparticles are subjected to descendent light, a part of light scattered (emission process) and the other part absorbed (non-emission process). The amount of energy dissipation in non-emission process mainly depends on material and volume of nanoparticles and it can be identified by absorption cross section. At the other hand, emission process which its characteristics are depend on volume, shape and surface characteristics of nanoparticles explains by scattering cross section. Sum of absorption and scattering processes which lead to light dissipation is called extinction cross section [75123].

Protactinium nanoparticles absorb energy of descendent light and generate some heat in the particle. The generated heat transferred to the surrounding environment and leads to increase in temperature of adjacent points to nanoparticles. Heat variations can be obtained by heat transfer equation [124-442].

\section{Simulation}

To calculate the generated heat in Protactinium nanoparticles, COMSOL software which works by Finite Element Method (FEM) was used. All simulations were made in 3D. Firstly, absorption and scattering cross section areas were calculated by optical module of software. Then, using heat module, temperature variations of nanoparticles and its surrounding environment were calculated by data from optical module [203-283]. In all cases, Protactinium nanoparticles are presented in water environment with dispersion coefficient of 1.84 and are subjected to flat wave emission with linear polarization. Intensity of descendent light is $1 \mathrm{~mW} / \mu^{2}{ }^{2}$. Dielectric constant of Protactinium is dependent on particle size [284-381].

Firstly, calculations were made for Protactinium nanospheres with radius of $5,10,15,20,25,30,35,40,45$ and 50 nanometers. The results show that by increase in nanoparticles size, extinction cross section area increases and maximum wavelength slightly shifts toward longer wavelengths. The maximum increase in temperature of nanospheres in surface Plasmon frequency is shown in Figure 1.

According to the graph, it can be seen that the generated heat is increased by increase in nanoparticles size. For $100(\mathrm{~nm})$ nanoparticles (sphere with 50 ( $\mathrm{nm}$ ) radius), the maximum increase in temperature is $83(\mathrm{~K})$. When nanoparticles size reaches to $150(\mathrm{~nm})$, increase in temperature is increased in spite of increase in extinction coefficient. In order to find the reason of this fact, ratio of absorption to extinction for various nanospheres in Plasmon frequency is shown in Figure 2.

Figure 2 shows that increasing the size of nanospheres leads to decrease in ratio of light absorption to total energy of descendent light so that for $150(\mathrm{~nm})$ nanosphere, scattering is larger than absorption. It seems that although increase in nanoparticles size leads to more dissipation of descendent light, the dissipation is in the form of scattering and hence, it cannot be effective on heat generation.

Heat distribution (Figure 3) shows that temperature is uniformly distributed throughout the nanoparticles which are due to high thermal conductivity of Protactinium.

In this section, core-shell structure of Protactinium and silica is chosen. The core of a nanosphere with $45(\mathrm{~nm})$ radius and silica layer thickness of $5,10,15,20,25,30,35,40,45$ and 50 nanometers are considered. The results show that increase in silica thickness leads to increase in extinction coefficient and shift in Plasmon wavelength of nanoparticles, to some extent.

According to Figure 4, silica shell causes to considerable increase in temperature of Protactinium nanoparticles but by more increase in silica thickness, its effects are decreased. Heat distribution (Figure 5) shows that temperature is uniformly distributed throughout metallic core as well as silica shell. However, silica temperature is considerably lower than core temperature due to its lower thermal conductivity. In fact, silica layer prohibits heat transfer from metal to the surrounding aqueous environment due to low thermal conductivity and hence, temperature of nanoparticles has more increase in temperature. Increasing the thickness of silica shell leads to increase in its thermal conductivity and hence, leads to attenuate in increase in nanoparticles temperature.

Figure 6 is drawn. This graph shows that variation of nanorod dimension ratio leads to considerable shift in Plasmon wavelength. This fact allows regulating the Plasmon frequency to place in near IR zone. Light absorption by body tissues is lower in this zone of spectrum and hence, nanorods are more appropriate for optothermal human cancer cells, tissues and tumors treatment methods.

Variations of temperature in Protactinium nanorods with two effective radius and various dimension ratios are shown in Figure 7. By increase in length (a) to radius (b) of nanorod, temperature is increased.

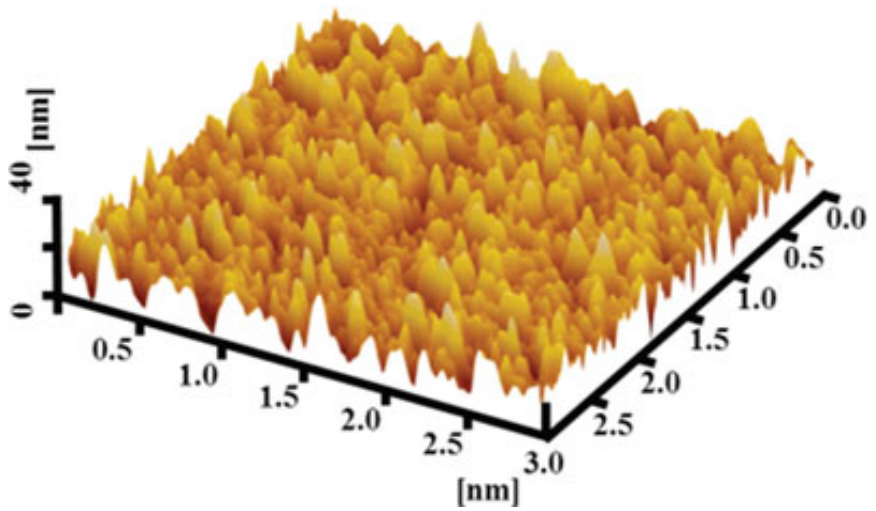

Figure 1. Maximum increase in temperature for Protactinium nanospheres

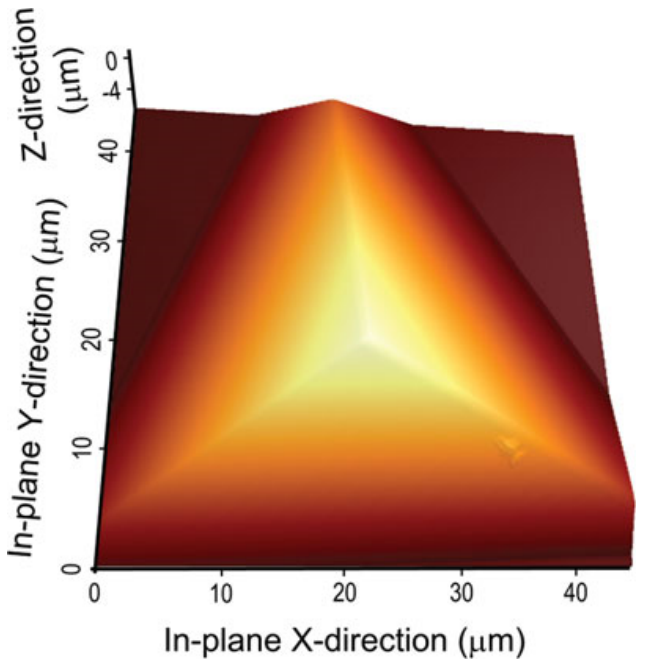

Figure 2. Variations of absorption to extinction ratio and scattering to extinction ratio for Protactinium nanospheres with various radiuses 
Heidari A (2020) Types of drug delivery system slide share of protactinium nanoparticles in human gum cancer cells, tissues and tumors treatment under synchrotron radiation

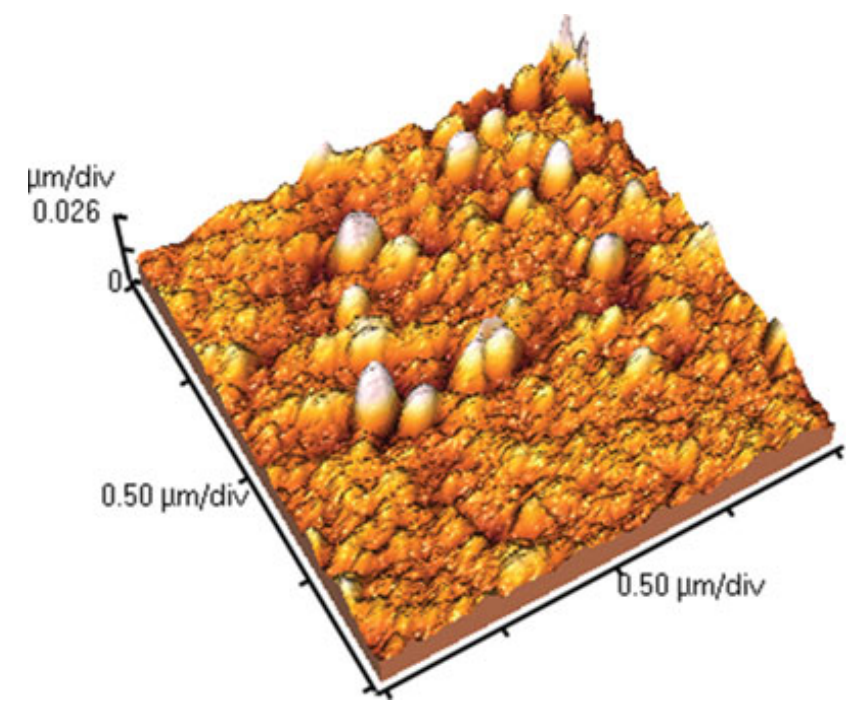

Figure 3. Maximum increase in temperature for spherical nanoparticles with radius of $45(\mathrm{~nm})$ at Plasmon wavelength of $685(\mathrm{~nm})$

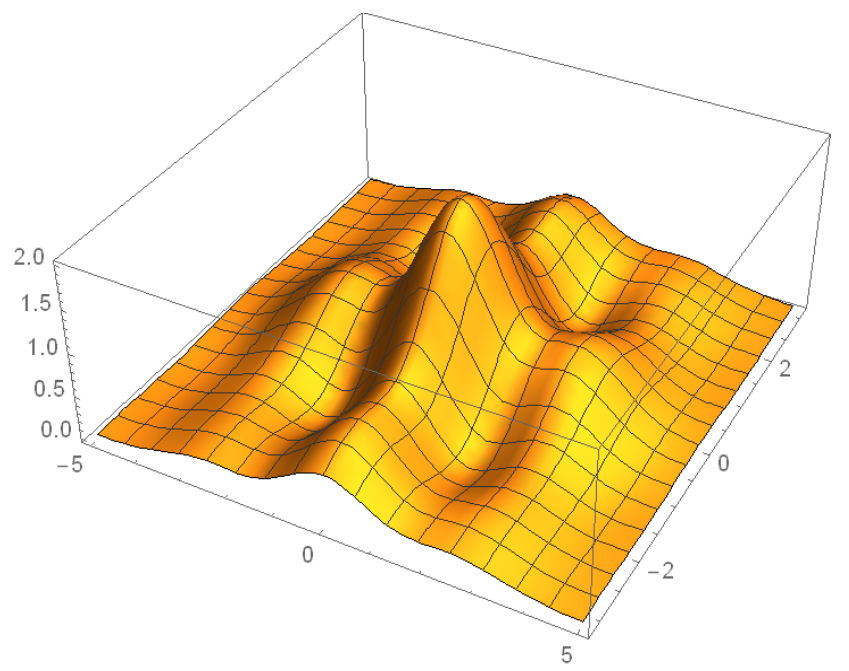

Figure 4. Maximum increase in temperature for core-shell Protactinium nanospheres with various thicknesses of silica shell

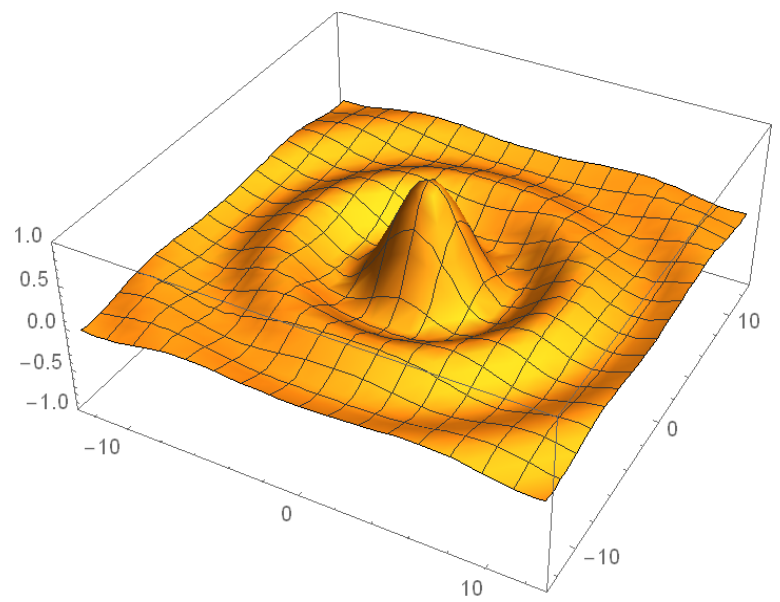

Figure 5. Maximum increase in temperature for core-shell nanoparticles with radius of $45(\mathrm{~nm})$ and silica thickness of 10 (nm) at Plasmon wavelength of 701 (nm) 


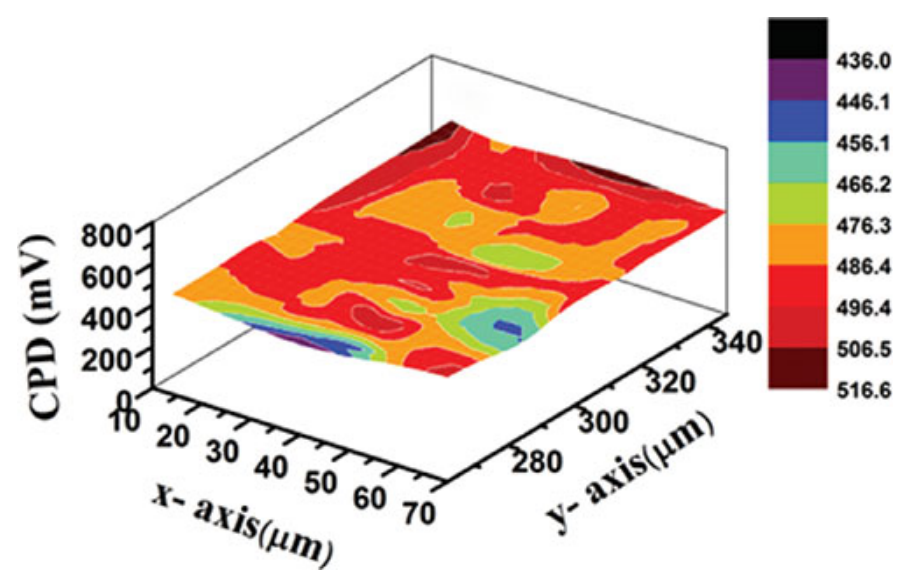

Figure 6. Extinction cross section area for Protactinium nanorods with effective radius of 45 $(\mathrm{nm})$ and various dimension ratios

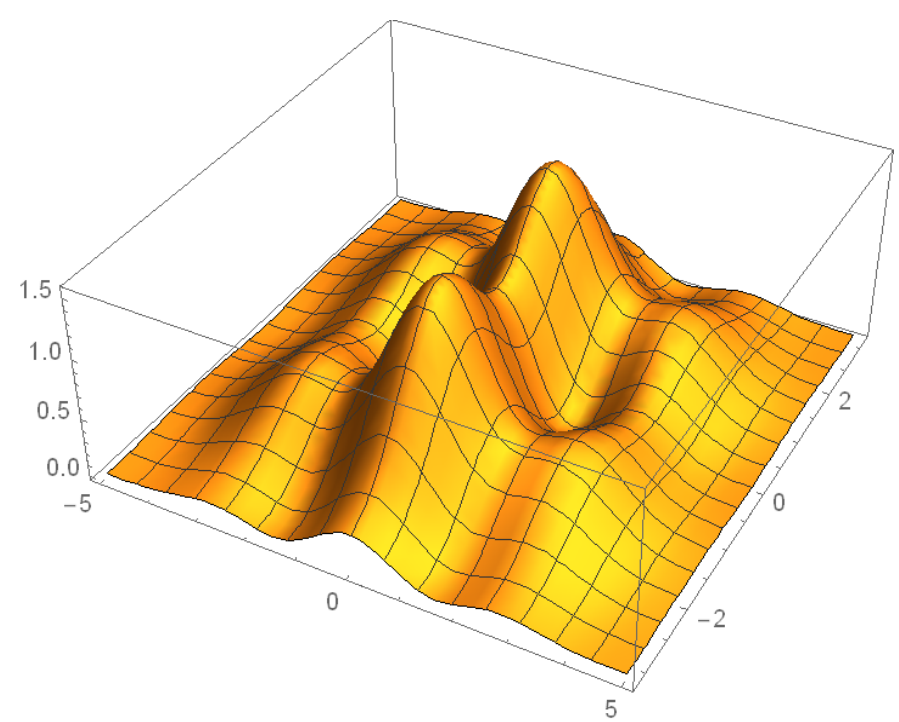

Figure 7. Maximum increase in temperature for nanorods with effective radius of 20 and $45(\mathrm{~nm})$ and various dimension ratios

\section{Conclusion and summary}

The calculations showed that in Protactinium nanoparticles, light absorption in Plasmon frequency causes to increase in temperature of the surrounding environment of nanoparticles. In addition, it showed that adding a thin silica layer around the Protactinium nanospheres increases their temperatures. Calculations of nanorods showed that due to ability for shifting surface Plasmon frequency toward longer wavelength as well as more increase in temperature, this nanostructure is more appropriate for medical applications such as optothermal human cancer cells, tissues and tumors treatments.

\section{Acknowledgements}

Authors are supported by an American International Standards Institute (AISI) Future Fellowship Grant FT12010093734718. We acknowledge Ms. Isabelle Villena for instrumental support and Dr. Michael N. Cocchi for constructing graphical abstract figures. We gratefully acknowledge Prof. Dr. Christopher Brown for proof reading the manuscript. Synchrotron beam time was awarded by the National Synchrotron Light Source (NSLS-II) under the merit-based proposal scheme.

\section{References}

1. Yu, P; Wu, J; Liu, S; Xiong, J; Jagadish, C; Wang, Z MDesign and Fabrication of Silicon Nanowires towards Efficient Solar Cells Nano Today2016, 11, 704-737, 101016/jnantod201610001

2. Sandhu, S; Fan, SCurrent-Voltage Enhancement of a Single Coaxial Nanowire Solar Cell ACS Photonics2015, 2, 1698-1704, 101021/acsphotonics5b00236

3. van Dam, D; Van Hoof, N J J; Cui, Y; van Veldhoven, P J; Bakkers, E P M; Gómez Rivas, J; Haverkort, J E MHigh-Efficiency Nanowire Solar Cells with Omnidirectionally Enhanced Absorption Due to Self-Aligned Indium-Tin-Oxide Mie Scatterers ACS Nano2016, 10, 11414-11419, 101021/acsnano6b06874

4. Luo, S; Yu, W B; He, Y; Ouyang, GSize-Dependent Optical Absorption Modulation of $\mathrm{Si} / \mathrm{Ge}$ and $\mathrm{Ge} / \mathrm{Si}$ Core/shell Nanowires with Different Cross-Sectional Geometries Nanotechnology2015, 26, 085702, 101088/0957-4484/26/8/085702

5. Yu, P; Yao, Y; Wu, J; Niu, X; Rogach, L; Wang, ZEffects of Plasmonic Metal CoreDielectric Shell Nanoparticles on the Broadband Light Absorption Enhancement in Thin Film Solar Cells Sci Rep2017, 7, 7696, 101038/s41598-017-08077-9

6. Gouda, M; Allam, N K; Swillam, M Efficient Fabrication Methodology of Wide Angle Black Silicon for Energy Harvesting Applications RSC Adv2017, 7, 26974-26982, 101039/C7RA03568C

7. Branz, H M; Yost, V E; Ward, S; Jones, K M; To, B; Stradins, PNanostructured Black Silicon and the Optical Reflectance of Graded-Density Surfaces Appl Phys Lett2009, 94, 231121, 101063/13152244

8. Fazio, B; Artoni, P; Antonía Iatí, M; D’Andrea, C; Lo Faro, M J; Del Sorbo, S; Pirotta S; Giuseppe Gucciardi, P; Musumeci, P; Salvatore Vasi, C; Saija, R; Galli, M; Priolo, F; Irrera, Strongly Enhanced Light Trapping in a Two-Dimensional Silicon Nanowire Random Fractal Array Light: Sci Appl2016, 5, e16062, 101038/1s201662

9. Ko, M-D; Rim, T; Kim, K; Meyyappan, M; Baek, C-KHigh Efficiency Silicon Sola Cell Based on Asymmetric Nanowire Sci Rep2015, 5, 11646, 101038/srep11646

10. Oh, J; Yuan, H C; Branz, H MAn 182\%-Efficient Black-Silicon Solar Cell Achieved through Control of Carrier Recombination in Nanostructures Nat Nanotechnol2012, 7, 743-748, 101038/nnano2012166

11. Lin, H; Xiu, F; Fang, M; Yip, S; Cheung, H Y; Wang, F; Han, N; Chan, K S; Wong, C Y Ho, J CRational Design of Inverted Nanopencil Arrays for Cost-Effective, Broadband, and Omnidirectional Light Harvesting ACS Nano2014, 8, 3752-3760, 101021/ $\mathrm{nn} 500418 \mathrm{x}$

12. Garnett, E; Yang, PLight Trapping in Silicon Nanowire Solar Cells Nano Lett2010, 10, 1082-1087, 101021/n1100161z

13. Misra, S; Yu, L; Foldyna, M; Roca I Cabarrocas, PHigh Efficiency and Stable Hydrogenated Amorphous Silicon Radial Junction Solar Cells Built on VLSGrown Silicon Nanowires Sol Energy Mater Sol Cells2013, 118, 90-95, 101016/ jsolmat201307036

14. Kelzenberg, M D; Boettcher, S W; Petykiewicz, J ; Turner-Evans, D B; Putnam, M C; Warren, E L; Spurgeon, J M; Briggs, R M; Lewis, N S; Atwater, H Enhanced Absorption and Carrier Collection in Si Wire Arrays for Photovoltaic Applications Nat Mater2010, 9, 239-244, 101038/nmat2635

15. Tian, B; Zheng, X; Kempa, T J; Fang, Y; Yu, N; Yu, G; Huang, J; Lieber, C MCoaxial Silicon Nanowires as Solar Cells and Nanoelectronic Power Sources Nature2007, 449, $885-889,101038$ /nature 06181

16. Razek, S; Swillam, M ; Allam, N KVertically Aligned Crystalline Silicon Nanowires with Controlled Diameters for Energy Conversion Applications: Experimental and Theoretical Insights J Appl Phys2014, 115, 194305, 101063/14876477

17. Dhindsa, N; Walia, J; Saini, S SA Platform for Colorful Solar Cells with Enhanced Absorption Nanotechnology2016, 27, 495203, 101088/0957-4484/27/49/495203

18. Dhindsa, N; Walia, J; Pathirane, M; Khodadad, I; Wong, W S; Saini, S SAdjustable Optical Response of Amorphous Silicon Nanowires Integrated with Thin Films Nanotechnology2016, 27, 145703, 101088/0957-4484/27/14/145703

19. Zhu, J; Yu, Z; Burkhard, G F; Hsu, C-M; Connor, S T; Xu, Y; Wang, Q; McGehee, M; Fan, S; Cui, YOptical Absorption Enhancement in Amorphous Silicon Nanowire and Nanocone Arrays Nano Lett2009, 9, 279-282, 101021/n1802886y

20. Klinger, D; Łusakowska, E; Zymierska, DNano-Structure Formed by Nanosecond Laser Annealing on Amorphous Si Surface Mater Sci Semicond Process2006, 9, 323 326, 101016/jmssp200601027 
Heidari A (2020) Types of drug delivery system slide share of protactinium nanoparticles in human gum cancer cells, tissues and tumors treatment under synchrotron radiation

21. Kumar, P; Krishna, M G; Bhattacharya, Excimer Laser Induced Nanostructuring of Silicon Surfaces J Nanosci Nanotechnol2009, 9, 3224-3232, 101166/jnn2009207

22. Kumar, PSurface Modulation of Silicon Surface by Excimer Laser at Laser Fluence below Ablation Threshold Appl Phys A: Mater Sci Process2010, 99, 245-250, 101007/ s00339-009-5510-x

23. Adikaari, D T; Silva, S R PThickness Dependence of Properties of Excimer Laser Crystallized Nano-Polycrystalline Silicon J Appl Phys2005, 97, 114305, $101063 / 11898444$

24. Adikaari, D T; Dissanayake, D M N M; Hatton, R ; Silva, S R PEfficient Laser Textured Nanocrystalline Silicon-Polymer Bilayer Solar Cells Appl Phys Lett2007, 90, 203514, $101063 / 12739365$

25. Adikaari, D T; Silva, S R PExcimer Laser Crystallization and Nanostructuring of Amorphous Silicon for Photovoltaic Applications Nano2008, 3, 117-126, 101142/ S1793292008000915

26. Tang, Y F; Silva, S R P; Boskovic, B O; Shannon, J M; Rose, M JElectron Field Emission from Excimer Laser Crystallized Amorphous Silicon Appl Phys Lett2002, $80,4154-4156,101063 / 11482141$

27. Jin, S; Hong, S; Mativenga, M; Kim, B; Shin, H H; Park, J K; Kim, T W; Jang, JLow Temperature Polycrystalline Silicon with Single Orientation on Glass by Blue Laser Annealing Thin Solid Films2016, 616, 838-841, 101016/jtsf201610026

28. Crouch, C H; Carey, J E; Warrender, J M; Aziz, M J; Mazur, E; Génin, F YComparison of Structure and Properties of Femtosecond and Nanosecond Laser-Structured Silicon Appl Phys Lett2004, 84, 1850-1852, 101063/11667004

29. Wu, C; Crouch, C H; Zhao, L; Carey, J E; Younkin, R; Levinson, J ; Mazur, E; Farrell, R M; Gothoskar, P; Karger, Near-Unity below-Band-Gap Absorption by Microstructured Silicon Appl Phys Lett2001, 78, 1850-1852, 101063/11358846

30. Pedraza, J; Fowlkes, J D; Lowndes, D HSilicon Microcolumn Arrays Grown by Nanosecond Pulsed-Excimer Laser Irradiation Appl Phys Lett1999, 74, 2322, $101063 / 1123838$

31. Pedraza, J; Fowlkes, J D; Jesse, S; Mao, C; Lowndes, D HSurface Micro-Structuring of Silicon by Excimer-Laser Irradiation in Reactive Atmospheres Appl Surf Sci2000, 168, 251-257, 101016/S0169-4332(00)00611-5

32. Porte, H P; Turchinovich, D; Persheyev, S; Fan, Y; Rose, M J; Jepsen, P UOn Ultrafas Photoconductivity Dynamics and Crystallinity of Black Silicon IEEE Trans Terahertz Sci Technol2013, 3, 331-341, 101109/TTHZ20132255917

33. Georgiev, D G; Baird, R J; Avrutsky, I; Auner, G; Newaz, GControllable ExcimerLaser Fabrication of Conical Nano-Tips on Silicon Thin Films Appl Phys Lett2004, 84, $4881-4883,101063 / 11762978$

34. Eizenkop, J; Avrutsky, I; Georgiev, D G; Chaudchary, VSingle-Pulse Excimer Laser Nanostructuring of Silicon: A Heat Transfer Problem and Surface Morphology J Appl Phys2008, 103, 094311, 101063/12910196

35. Eizenkop, J; Avrutsky, I; Auner, G; Georgiev, D G; Chaudhary, VSingle Pulse Excimer Laser Nanostructuring of Thin Silicon Films: Nanosharp Cones Formation and a Heat Transfer Problem J Appl Phys2007, 101, 094301, 101063/12720185

36. Hong, L; Wang, X C; Zheng, H Y; He, L; Wang, H; Yu, H Y; RusliFemtosecond Laser Induced Nanocone Structure and Simultaneous Crystallization of $16 \mu \mathrm{M}$ Amorphous Silicon Thin Film for Photovoltaic Application J Phys D: Appl Phys2013, 46, 195109, 101088/0022-3727/46/19/195109

37. Hong, L; Wang, X; Rusli; Wang, H; Zheng, H; Yu, HCrystallization and Surface Texturing of Amorphous-Si Induced by UV Laser for Photovoltaic Application J Appl Phys2012, 111, 043106, 101063/13686612

38. Magdi, S; Swillam, M Broadband Absorption Enhancement in Amorphous Si Solar Cells Using Metal Gratings and Surface Texturing Proc SPIE2017, 10099, 1009912, $101117 / 122253326$

39. Diedenhofen, S L; Janssen, O T ; Grzela, G; Bakkers, E P M; Gómez Rivas, JStrong Geometrical Dependence of the Absorption of Light in Arrays of Semiconductor Nanowires ACS Nano2011, 5, 2316-2323, 101021/nn103596n

40. Jäger, S T; Strehle, SDesign Parameters for Enhanced Photon Absorption in Vertically Aligned Silicon Nanowire Arrays Nanoscale Res Lett2014, 9, 511, 101186/1556-276X9-511

41. Gouda, M; Elsayed, M Y; Khalifa, E; Ismail, Y; Swillam, M Lithography-Free WideAngle Antireflective Self-Cleaning Silicon Nanocones Opt Lett2016, 41, 3575, 101364/OL41003575
42. Magdi, S; Swillam, M Optical Analysis of Si-Tapered Nanowires/low Band Gap Polymer Hybrid Solar Cells Proc SPIE2017, 10099, 100991D, 101117/122253299

43. Jiang, Y; Gong, X; Qin, R; Liu, H; Xia, C; Ma, HEfficiency Enhancement Mechanism for $\operatorname{Poly}(3, \quad 4-$-ethylenedioxythiophene):Poly(styrenesulfonate)/Silicon Nanowires Hybrid Solar Cells Using Alkali Treatment Nanoscale Res Lett2016, 11, 267, 101186 s11671-016-1450-5

44. Gong, X; Jiang, Y; Li, M; Liu, H; Ma, HHybrid Tapered Silicon nanowire/PEDOT:PSS Solar Cells RSC Adv2015, 5 (14), 10310-10317, 101039/C4RA16603E

45. Mohammad, N SUnderstanding Quantum Confinement in Nanowires: Basics, Applications and Possible Laws J Phys: Condens Matter2014, 26, 423202, 101088/0953-8984/26/42/423202

46. Zhang, ; Luo, S; Ouyang, G; Yang, G WStrain-Induced Optical Absorption Properties of Semiconductor Nanocrystals J Chem Phys2013, 138, 244702, 101063/14811222

47. He, Y; Yu, W; Ouyang, GShape-Dependent Conversion Efficiency of Si Nanowire Solar Cells with Polygonal Cross-Sections J Appl Phys2016, 119, 225101, 101063/14953377

48. Tchakarov, S; Das, D; Saadane, O; Kharchenko, V; Suendo, V; Kail, F; Roca i Cabarrocas, PHelium versus Hydrogen Dilution in the Optimization of Polymorphous Silicon Solar Cells J Non-Cryst Solids2004, 338-340, 668-672, 101016/jjnoncrysol200403068

49. Roszairi, H; Rahman, S High Deposition Rate Thin Film Hydrogenated Amorphous Silicon Prepared by Dc Plasma Enhanced Chemical Vapour Deposition of Helium Diluted Silane IEEE International Conference on Semiconductor Electronics, 2002 Proceedings ICSE 2002, Panang, Malaysia, Dec 19-21, 2002; IEEE: New York, NY, USA, 2002; pp 300-303, DOI: 101109/SMELEC20021217830

50. N'Guyen, T T T; Duong, H T T; Basuki, J; Montembault, V; Pascual, S; Guibert, C; Fresnais, J; Boyer, C; Whittaker, M R; Davis, T P; Fontaine, LFunctional Iron Oxide Magnetic Nanoparticles with Hyperthermia-Induced Drug Release Ability by Using a Combination of Orthogonal Click Reactions Angew Chem, Int Ed2013, 52, 14152 14156, 101002/anie201306724

51. Xu, Z; Zhao, Y; Wang, X; Lin, TA Thermally Healable Polyhedral Oligomeric Silsesquioxane (POSS) Nanocomposite based on Diels-Alder chemistry Chem Commun2013, 49, 6755-6757, 101039/c3cc43432j

52. Engel, T; Kickelbick, GSelf-Healing Nanocomposites from Silica - Polymer Core Shell Nanoparticles Polym Int2014, 63, 915-923, 101002/pi4642

53. Engel, T; Kickelbick, GFuran-Modified Spherosilicates as Building Blocks for SelfHealing Materials Eur J Inorg Chem2015, 2015, 1226-1232, 101002/ejic201402551

54. Torres-Lugo, M; Rinaldi, CThermal Potentiation of Chemotherapy by Magnetic Nanoparticles Nanomedicine2013, 8, 1689-1707, 102217/nnm13146

55. Hohlbein, N; Shaaban, ; Bras, R; Pyckhout-Hintzen, W; Schmidt, MSelf-healing Dynamic Bond-based Rubbers: Understanding the Mechanisms in Ionomeric Elastomer Model Systems Phys Chem Chem Phys2015, 17, 21005-21017, 101039/C5CP00620A

56. Wu, C-S; Kao, T-H; Li, H-Y; Liu, Y-LPreparation of Polybenzoxazine-functionalized Fe3O4 Nanoparticles through in situ Diels-Alder Polymerization for High Performance Magnetic Polybenzoxazine/Fe3O4 Nanocomposites Compos Sci Technol2012, 72, 1562-1567, 101016/jcompscitech201206018

57. Menon, V; Madras, G; Bose, SUltrafast Self-Healable Interfaces in Polyurethane Nanocomposites Designed Using Diels-Alder "Click" as an Efficient Microwave Absorber ACS Omega2018, 3, 1137-1146, 101021/acsomeg7b01845

58. Engel, T; Kickelbick, GThermoreversible Reactions on Inorganic Nanoparticle Surfaces: Diels-Alder Reactions on Sterically Crowded Surfaces Chem Mater2013, $25,149-157,101021 / \mathrm{cm} 303049 \mathrm{k}$

59. Schäfer, S; Kickelbick, GSelf-Healing Polymer Nanocomposites based on Diels-Alderreactions with Silica Nanoparticles: The Role of the Polymer Matrix Polymer2015, 69, 357-368, 101016/jpolymer201503017

60. Park, J S; Darlington, T; Starr, F; Takahashi, K; Riendeau, J; Thomas Hahn, HMultiple Healing Effect of Thermally Activated Self-Healing Composites based on Diels-Alder reaction Compos Sci Technol2010, 70, 2154-2159, 101016/jcompscitech201008017

61. Li, J; Liang, J; Li, L; Ren, F; Hu, W; Li, J; Qi, S; Pei, QHealable Capacitive Touch Screen Sensors Based on Transparent Composite ElectrodesComprising Silver Nanowires and a Furan/Maleimide Diels-Alder Cycloaddition Polymer ACS Nano2014, 8, 12874 $12882,101021 / \mathrm{nn} 506610 \mathrm{p}$

62. Sun, S; Zeng, H; Robinson, D B; Raoux, S; Rice, P M; Wang, S X; Li, GMonodisperse MFe2O4 (M = Fe, Co, Mn) Nanoparticles J Am Chem Soc2004, 126, 273-279, 101021/ja0380852 
Heidari A (2020) Types of drug delivery system slide share of protactinium nanoparticles in human gum cancer cells, tissues and tumors treatment under synchrotron radiation

63. Frison, R; Cernuto, G; Cervellino, ; Zaharko, O; Colonna, G M; Guagliardi, ; Masciocchi, NMagnetite-Maghemite Nanoparticles in the 5-15 nm Range: Correlating the Core-Shell Composition and the Surface Structure to the Magnetic Properties A Total Scattering Study Chem Mater2013, 25, 4820-4827, 101021/cm403360f

64. Santoyo Salazar, J; Perez, L; de Abril, O; Truong Phuoc, L; Ihiawakrim, D; Vazquez, M; Greneche, J-M; Begin-Colin, S; Pourroy, GMagnetic Iron Oxide Nanoparticles in 10-40 nm Range: Composition in Terms of Magnetite/Maghemite Ratio and Effect on the Magnetic Properties Chem Mater2011, 23, 1379-1386, 101021/cm103188a

65. Guerrero, G; Mutin, P H; Vioux, Anchoring of Phosphonate and Phosphinate Coupling Molecules on Titania Particles Chem Mater2001, 13, 4367-4373, 101021/cm001253u

66. Babu, K; Dhamodharan, RGrafting of Poly(methyl methacrylate) Brushes from Magnetite Nanoparticles Using a Phosphonic Acid Based Initiator by Ambient Temperature Atom Transfer Radical Polymerization (ATATRP) Nanoscale Res Lett2008, 3, 109-117, 101007/s11671-008-9121-9

67. Mohapatra, S; Pramanik, PSynthesis and Stability of Functionalized Iron Oxide Nanoparticles using Organophosphorus Coupling Agents Colloids Surf, A2009, 339, 35-42, 101016/jcolsurf200901009

68. Larsen, B ; Hurst, K M; Ashurst, W R; Serkova, N J; Stoldt, C RMono- and Dialkoxysilane Surface Modification of Superparamagnetic Iron Oxide Nanoparticles for Application as Magnetic Resonance Imaging Contrast Agents J Mater Res2012, 27, 1846-1852, 101557/jmr2012160

69. Davis, K; Qi, B; Witmer, M; Kitchens, C L; Powell, B ; Mefford, O TQuantitative Measurement of Ligand Exchange on Iron Oxides via Radiolabeled Oleic Acid Langmuir2014, 30, 10918-10925, 101021/la502204g

70. Feichtenschlager, B; Pabisch, S; Peterlik, H; Kickelbick, GNanoparticle Assemblies as Probes for Self-Assembled Monolayer Characterization: Correlation between Surface Functionalization and Agglomeration Behavior Langmuir2012, 28, 741-750, 101021/ la2023067

71. Musa, O MHandbook of Maleic Anhydride Based Materials: Syntheses, Properties and Applications;Springer International Publishing: Switzerland, 2016; p 175ff

72. Sauer, R; Froimowicz, P; Scholler, K; Cramer, J M; Ritz, S; Mailander, V; Landfester, KDesign, Synthesis, and Miniemulsion Polymerization of New Phosphonate Surfmers and Application Studies of the Resulting Nanoparticles as Model Systems for Biomimetic Mineralization and Cellular Uptake Chem - Eur J2012, 18, 5201-5212, 101002/chem201103256

73. Lu, C; Bhatt, L R; Jun, H Y; Park, S H; Chai, K YCarboxyl-Polyethylene GlycolPhosphoric Acid: A Ligand for highly stabilized Iron Oxide Nanoparticles J Mater Chem2012, 22, 19806-19811, 101039/c2jm34327d

74. Patsula, V; Kosinova, L; Lovric, M; Ferhatovic Hamzic, L; Rabyk, M; Konefal, R Paruzel, ; Slouf, M; Herynek, V; Gajovic, S; Horak, DSuperparamagnetic Fe3O4 Nanoparticles: Synthesis by Thermal Decomposition of Iron(III) Glucuronate and Application in Magnetic Resonance Imaging ACS Appl Mater Interfaces2016, 8, 7238-7247, 101021/acsami5b12720

75. Pothayee, N; Balasubramaniam, S; Davis, R M; Riffle, J S; Carroll, M R J; Woodward, R C; St Pierre, T GSynthesis of 'ready-to-adsorb' Polymeric Nanoshells for Magnetic Iron Oxide Nanoparticles via Atom Transfer Radical Polymerization Polymer2011, 52, 1356-1366, 101016/jpolymer201101047

76. Daou, J; Begin-Colin, S; Grenèche, J M; Thomas, F; Derory, ; Bernhardt, P; Legaré, P; Pourroy, GPhosphate Adsorption Properties of Magnetite-Based Nanoparticles Chem Mater2007, 19, 4494-4505, 101021/cm071046v

77. Breucker, L; Landfester, K; Taden, Phosphonic Acid-Functionalized Polyurethane Dispersions with Improved Adhesion Properties ACS Appl Mater Interfaces2015, 7, 24641-24648, 101021/acsami5b06903

78. Sahoo, Y; Pizem, H; Fried, T; Golodnitsky, D; Burstein, L; Sukenik, C N; Markovich, GAlkyl Phosphonate/Phosphate Coating on Magnetite Nanoparticles: A Comparison with Fatty Acids Langmuir2001, 17, 7907-7911, 101021/la010703+

79. Longo, R C; Cho, K; Schmidt, W G; Chabal, Y J; Thissen, PMonolayer Doping via Phosphonic Acid Grafting on Silicon: Microscopic Insight from Infrared Spectroscopy and Density Functional Theory Calculations Adv Funct Mater2013, 23, 3471-3477, 101002/adfm201202808

80. Luschtinetz, R; Seifert, G; Jaehne, E; Adler, H-J PInfrared Spectra of Alkylphosphonic Acid Bound to Aluminium Surfaces Macromol Symp2007, 254, 248-253, 101002/ masy 200750837

81. Thomas, L C; Chittenden, R Characteristic Infrared Absorption Frequencies of Organophosphorus Compounds-II P-O-(X) Bonds Spectrochim Acta1964, 20, 489502, 101016/0371-1951(64)80044-8
82. Quinones, R; Shoup, D; Behnke, G; Peck, C; Agarwal, S; Gupta, R K; Fagan, J W Mueller, K T; Iuliucci, R J; Wang, QStudy of Perfluorophosphonic Acid Surface Modifications on Zinc Oxide Nanoparticles Materials2017, 10, 1-16, 103390/ ma10121363

83. Lalatonne, Y; Paris, C; Serfaty, J M; Weinmann, P; Lecouvey, M; Motte, LBisPhosphonates-Ultra Small Superparamagnetic Iron Oxide Nanoparticles: A Platform towards Diagnosis and Therapy Chem Commun2008, 2553-2555, 101039/b801911h

84. Jastrzebski, W; Sitarz, M; Rokita, M; Bulat, KInfrared Spectroscopy of different Phosphates Structures Spectrochim Acta, Part A2011, 79, 722-727, 101016/ jsa201008044

85. Brodard-Severac, F; Guerrero, G; Maquet, J; Florian, P; Gervais, C; Mutin, P HHighField 170 MAS NMR Investigation of Phosphonic Acid Monolayers on Titani Chem Mater2008, 20, 5191-5196, 101021/cm8012683

86. Brice-Profeta, S; Arrio, M ; Tronc, E; Menguy, N; Letard, I; CartierditMoulin, C; Noguès, M; Chanéac, C; Jolivet, J P; Sainctavit, PMagnetic Order in g-Fe2O3 Nanoparticles: A XMCD Study J Magn Magn Mater2005, 288, 354-365, 101016/ jjmmm200409120

87. Tronc, E; Ezzir, ; Cherkaoui, R; Chanéac, C; Noguès, M; Kachkachi, H; Fiorani, D; Testa, M; Grenèche, J M; Jolivet, J PSurface-Related Properties of g-Fe2O3 Nanoparticles J Magn Magn Mater2000, 221, 63-79, 101016/S0304-8853(00)00369-3

88. Yee, C; Kataby, G; Ulman, ; Prozorov, T; White, H; King, ; Rafailovich, M; Sokolov, J; Gedanken, Self-Assembled Monolayers of Alkanesulfonic and -phosphonic Acids on Amorphous Iron Oxide Nanoparticles Langmuir1999, 15, 7111-7115, 101021/ la990663y

89. Jolivet, J P; Chaneac, C; Tronc, EIron Oxide Chemistry From Molecular Clusters to Extended Solid Networks Chem Commun2004, 481-487, 101039/B304532N

90. Campbell, V E; Tonelli, M; Cimatti, I; Moussy, J B; Tortech, L; Dappe, Y J; Riviere, E; Guillot, R; Delprat, S; Mattana, R; Seneor, P; Ohresser, P; Choueikani, F; Otero, E; Koprowiak, F; Chilkuri, V G; Suaud, N; Guihery, N; Galtayries, ; Miserque, F; Arrio, M ; Sainctavit, P; Mallah, TEngineering the Magnetic Coupling and Anisotropy at the Molecule-Magnetic Surface Interface in Molecular Spintronic Devices Nat Commun2016, 7, 13646-10, 101038/ncomms13646

91. Pabisiak, T; Winiarski, M J; Ossowski, T; Kiejna, Adsorption of Gold SubnanoStructures on a Magnetite (111) Surface and their Interaction with CO Phys Chem Chem Phys2016, 18, 18169-18179, 101039/C6CP03222B

92. Gomes, R; Hassinen, ; Szczygiel, ; Zhao, Q; Vantomme, ; Martins, J C; Hens, ZBinding of Phosphonic Acids to CdSe Quantum Dots: A Solution NMR Study J Phys Chem Lett2011, 2, 145-152, 101021/jz1016729

93. Chun, Y-J; Park, J-N; Oh, G-M; Hong, S-I; Kim, Y-JSynthesis of $\omega$-Phthalimidoalkylphosphonates Synthesis1994, 1994, 909-910, 101055/s-199425599

94. Heidari, C Brown, "Study of Composition and Morphology of Cadmium Oxide (CdO) Nanoparticles for Eliminating Cancer Cells", J Nanomed Res, Volume 2, Issue 5, 20 Pages, 2015

95. Heidari, C Brown, "Study of Surface Morphological, Phytochemical and Structural Characteristics of Rhodium (III) Oxide (Rh2O3) Nanoparticles", International Journal of Pharmacology, Phytochemistry and Ethnomedicine, Volume 1, Issue 1, Pages 15-19, 2015

96. Heidari, "An Experimental Biospectroscopic Study on Seminal Plasma in Determination of Semen Quality for Evaluation of Male Infertility”, Int J Adv Technol 7: e007, 2016

97. Heidari, "Extraction and Preconcentration of N-Tolyl-Sulfonyl-PhosphoramidSaeure-Dichlorid as an Anti-Cancer Drug from Plants: A Pharmacognosy Study", J Pharmacogn Nat Prod 2: e103, 2016

98. Heidari, "A Thermodynamic Study on Hydration and Dehydration of DNA and RNAAmphiphile Complexes", J Bioeng Biomed Sci S: 006, 2016

99. Heidari, "Computational Studies on Molecular Structures and Carbonyl and Ketene Groups' Effects of Singlet and Triplet Energies of Azidoketene $\mathrm{O}=\mathrm{C}=\mathrm{CH}-\mathrm{NNN}$ and Isocyanatoketene $\mathrm{O}=\mathrm{C}=\mathrm{CH}-\mathrm{N}=\mathrm{C}=\mathrm{O}$ ", $\mathrm{J}$ Appl Computat Math 5: e142, 2016

100. Heidari, "Study of Irradiations to Enhance the Induces the Dissociation of Hydrogen Bonds between Peptide Chains and Transition from Helix Structure to Random Coil Structure Using ATR-FTIR, Raman and 1HNMR Spectroscopies", J Biomol Res Ther 5: e146, 2016

101. Heidari, "Future Prospects of Point Fluorescence Spectroscopy, Fluorescence Imaging and Fluorescence Endoscopy in Photodynamic Therapy (PDT) for Cancer Cells", J Bioanal Biomed 8: e135, 2016 
Heidari A (2020) Types of drug delivery system slide share of protactinium nanoparticles in human gum cancer cells, tissues and tumors treatment under synchrotron radiation

102. Heidari, "A Bio-Spectroscopic Study of DNA Density and Color Role as Determining Factor for Absorbed Irradiation in Cancer Cells", Adv Cancer Prev 1: e102, 2016

103. Heidari, "Manufacturing Process of Solar Cells Using Cadmium Oxide (CdO) and Rhodium (III) Oxide (Rh2O3) Nanoparticles", J Biotechnol Biomater 6: e125, 2016

104. Heidari, "A Novel Experimental and Computational Approach to Photobiosimulation of Telomeric DNA/RNA: A Biospectroscopic and Photobiological Study", J Res Development 4: 144, 2016

105. Heidari, "Biochemical and Pharmacodynamical Study of Microporous Molecularly Imprinted Polymer Selective for Vancomycin, Teicoplanin, Oritavancin, Telavancin and Dalbavancin Binding", Biochem Physiol 5: e146, 2016

106. Heidari, "Anti-Cancer Effect of UV Irradiation at Presence of Cadmium Oxide (CdO) Nanoparticles on DNA of Cancer Cells: A Photodynamic Therapy Study", Arch Cancer Res 4: 1, 2016

107. Heidari, "Biospectroscopic Study on Multi-Component Reactions (MCRs) in Two A-Type and B-Type Conformations of Nucleic Acids to Determine Ligand Binding Modes, Binding Constant and Stability of Nucleic Acids in Cadmium Oxide (CdO) Nanoparticles-Nucleic Acids Complexes as Anti-Cancer Drugs", Arch Cancer Res 4: 2,2016

108. Heidari, "Simulation of Temperature Distribution of DNA/RNA of Human Cancer Cells Using Time-Dependent Bio-Heat Equation and Nd: YAG Lasers", Arch Cancer Res 4: 2, 2016

109. Heidari, "Quantitative Structure-Activity Relationship (QSAR) Approximation for Cadmium Oxide (CdO) and Rhodium (III) Oxide (Rh2O3) Nanoparticles as AntiCancer Drugs for the Catalytic Formation of Proviral DNA from Viral RNA Using Multiple Linear and Non-Linear Correlation Approach", Ann Clin Lab Res 4: 1, 2016

110. Heidari, "Biomedical Study of Cancer Cells DNA Therapy Using Laser Irradiations at Presence of Intelligent Nanoparticles", J Biomedical Sci 5: 2, 2016

111. Heidari, "Measurement the Amount of Vitamin D2 (Ergocalciferol), Vitamin D3 (Cholecalciferol) and Absorbable Calcium $(\mathrm{Ca} 2+)$, Iron (II) $(\mathrm{Fe} 2+)$, Magnesium $(\mathrm{Mg} 2+)$, Phosphate (PO4-) and Zinc ( $\mathrm{Zn} 2+)$ in Apricot Using High-Performance Liquid Chromatography (HPLC) and Spectroscopic Techniques", J Biom Biostat 7: 292,2016

112. Heidari, "Spectroscopy and Quantum Mechanics of the Helium Dimer (He2+), Neon Dimer (Ne2+), Argon Dimer (Ar2+), Krypton Dimer (Kr2+), Xenon Dimer (Xe2+), Radon Dimer(Rn2+) and Ununoctium Dimer (Uuo2+) Molecular Cations", Chem Sci J 7: e112, 2016

113. Heidari, "Human Toxicity Photodynamic Therapy Studies on DNA/RNA Complexes as a Promising New Sensitizer for the Treatment of Malignant Tumors Using BioSpectroscopic Techniques", J Drug Metab Toxicol 7: e129, 2016

114. Heidari, "Novel and Stable Modifications of Intelligent Cadmium Oxide (CdO) Nanoparticles as Anti-Cancer Drug in Formation of Nucleic Acids Complexes fo Human Cancer Cells' Treatment”, Biochem Pharmacol (Los Angel) 5: 207, 2016

115. Heidari, "A Combined Computational and QM/MM Molecular Dynamics Study on Boron Nitride Nanotubes (BNNTs), Amorphous Boron Nitride Nanotubes (aBNNTs) and Hexagonal Boron Nitride Nanotubes (h-BNNTs) as Hydrogen Storage", Struct Chem Crystallogr Commun 2: 1, 2016

116. Heidari, "Pharmaceutical and Analytical Chemistry Study of Cadmium Oxide (CdO) Nanoparticles Synthesis Methods and Properties as Anti-Cancer Drug and its Effect on Human Cancer Cells", Pharm Anal Chem Open Access 2: 113, 2016

117. Heidari, "A Chemotherapeutic and Biospectroscopic Investigation of the Interaction of Double-Standard DNA/RNA-Binding Molecules with Cadmium Oxide (CdO) and Rhodium (III) Oxide (Rh2O3) Nanoparticles as Anti-Cancer Drugs for Cancer Cells' Treatment", Chemo Open Access 5: e129, 2016

118. Heidari, "Pharmacokinetics and Experimental Therapeutic Study of DNA and Other Biomolecules Using Lasers: Advantages and Applications", J Pharmacokinet Exp Ther 1: e005, 2016

119. Heidari, "Determination of Ratio and Stability Constant of DNA/RNA in Human Cancer Cells and Cadmium Oxide (CdO) Nanoparticles Complexes Using Analytical Electrochemical and Spectroscopic Techniques", Insights Anal Electrochem 2: 1, 2016

120. Heidari, "Discriminate between Antibacterial and Non-Antibacterial Drugs Artificial Neutral Networks of a Multilayer Perceptron (MLP) Type Using a Set of Topological Descriptors", J Heavy Met Toxicity Dis 1: 2, 2016

121. Heidari, "Combined Theoretical and Computational Study of the BelousovZhabotinsky Chaotic Reaction and Curtius Rearrangement for Synthesis of Mechlorethamine, Cisplatin, Streptozotocin, Cyclophosphamide, Melphalan, Busulphan and BCNU as Anti-Cancer Drugs", Insights Med Phys 1: 2, 2016
122. Heidari, "A Translational Biomedical Approach to Structural Arrangement of Amino Acids' Complexes: A Combined Theoretical and Computational Study", Transl Biomed 7: 2, 2016

123. Heidari, "Ab Initio and Density Functional Theory (DFT) Studies of Dynamic NMR Shielding Tensors and Vibrational Frequencies of DNA/RNA and Cadmium Oxide (CdO) Nanoparticles Complexes in Human Cancer Cells", J Nanomedine Biotherapeutic Discov 6: e144, 2016

124. Heidari, "Molecular Dynamics and Monte-Carlo Simulations for Replacement Sugars in Insulin Resistance, Obesity, LDL Cholesterol, Triglycerides, Metabolic Syndrome, Type 2 Diabetes and Cardiovascular Disease: A Glycobiological Study", J Glycobiol 5: e111, 2016

125. Heidari, "Synthesis and Study of 5-[(Phenylsulfonyl)Amino]-1,3,4-Thiadiazole-2Sulfonamide as Potential Anti-Pertussis Drug Using Chromatography and Spectroscopy Techniques", Transl Med (Sunnyvale) 6: e138, 2016

126. Heidari, "Nitrogen, Oxygen, Phosphorus and Sulphur Heterocyclic Anti-Cancer Nano Drugs Separation in the Supercritical Fluid of Ozone (O3) Using SoaveRedlich-Kwong (SRK) and Pang-Robinson (PR) Equations", Electronic J Biol 12: 4, 2016

127. Heidari, "An Analytical and Computational Infrared Spectroscopic Review of Vibrational Modes in Nucleic Acids", Austin J Anal Pharm Chem 3 (1): 1058, 2016

128. Heidari, C Brown, "Phase, Composition and Morphology Study and Analysis of OsPd/HfC Nanocomposites", Nano Res Appl 2: 1, 2016

129. Heidari, C Brown, "Vibrational Spectroscopic Study of Intensities and Shifts of Symmetric Vibration Modes of Ozone Diluted by Cumene", International Journal of Advanced Chemistry, 4 (1) 5-9, 2016

130. Heidari, "Study of the Role of Anti-Cancer Molecules with Different Sizes for Decreasing Corresponding Bulk Tumor Multiple Organs or Tissues", Arch Can Res 4: 2,2016

131. Heidari, "Genomics and Proteomics Studies of Zolpidem, Necopidem, Alpidem, Saripidem, Miroprofen, Zolimidine, Olprinone and Abafungin as Anti-Tumor, Peptide Antibiotics, Antiviral and Central Nervous System (CNS) Drugs”, J Data Mining Genomics \& Proteomics 7: e125, 2016

132. Heidari, "Pharmacogenomics and Pharmacoproteomics Studies of Phosphodiesterase-5 (PDE5) Inhibitors and Paclitaxel Albumin-Stabilized Nanoparticles as Sandwiched Anti-Cancer Nano Drugs between Two DNA/RNA Molecules of Human Cancer Cells", J Pharmacogenomics Pharmacoproteomics 7: e153, 2016

133. Heidari, "Biotranslational Medical and Biospectroscopic Studies of Cadmium Oxide (CdO) Nanoparticles-DNA/RNA Straight and Cycle Chain Complexes as Potent Anti-Viral, Anti-Tumor and Anti-Microbial Drugs: A Clinical Approach", Transl Biomed 7: 2, 2016

134. Heidari, "A Comparative Study on Simultaneous Determination and Separation of Adsorbed Cadmium Oxide (CdO) Nanoparticles on DNA/RNA of Human Cancer Cells Using Biospectroscopic Techniques and Dielectrophoresis (DEP) Method", Arch Can Res 4: 2, 2016

135. Heidari, "Cheminformatics and System Chemistry of Cisplatin, Carboplatin, Nedaplatin, Oxaliplatin, Heptaplatin and Lobaplatin as Anti-Cancer Nano Drugs: A Combined Computational and Experimental Study", J Inform Data Min 1: 3, 2016

136. Heidari, "Linear and Non-Linear Quantitative Structure-Anti-Cancer-Activity Relationship (QSACAR) Study of Hydrous Ruthenium (IV) Oxide (RuO2) Nanoparticles as Non-Nucleoside Reverse Transcriptase Inhibitors (NNRTIs) and Anti-Cancer Nano Drugs", J Integr Oncol 5: e110, 2016

137. Heidari, "Synthesis, Characterization and Biospectroscopic Studies of Cadmium Oxide (CdO) Nanoparticles-Nucleic Acids Complexes Absence of Soluble Polymer as a Protective Agent Using Nucleic Acids Condensation and Solution Reduction Method", J Nanosci Curr Res 1: e101, 2016

138. Heidari, "Coplanarity and Collinearity of 4'-Dinonyl-2,2'-Bithiazole in One Domain of Bleomycin and Pingyangmycin to be Responsible for Binding of Cadmium Oxide (CdO) Nanoparticles to DNA/RNA Bidentate Ligands as Anti-Tumor Nano Drug", Int J Drug Dev \& Res 8: 007-008, 2016

139. Heidari, "A Pharmacovigilance Study on Linear and Non-Linear Quantitative Structure (Chromatographic) Retention Relationships (QSRR) Models for the Prediction of Retention Time of Anti-Cancer Nano Drugs under Synchrotron Radiations", J Pharmacovigil 4: e161, 2016

140. Heidari, "Nanotechnology in Preparation of Semipermeable Polymers", J Adv Chem Eng 6: 157, 2016 
Heidari A (2020) Types of drug delivery system slide share of protactinium nanoparticles in human gum cancer cells, tissues and tumors treatment under synchrotron radiation

141. Heidari, "A Gastrointestinal Study on Linear and Non-Linear Quantitative Structure (Chromatographic) Retention Relationships (QSRR) Models for Analysis 5Aminosalicylates Nano Particles as Digestive System Nano Drugs under Synchrotron Radiations", J Gastrointest Dig Syst 6: e119, 2016

142. Heidari, "DNA/RNA Fragmentation and Cytolysis in Human Cancer Cells Treated with Diphthamide Nano Particles Derivatives", Biomedical Data Mining 5: e102, 2016

143. Heidari, "A Successful Strategy for the Prediction of Solubility in the Construction of Quantitative Structure-Activity Relationship (QSAR) and Quantitative StructureProperty Relationship (QSPR) under Synchrotron Radiations Using Genetic Function Approximation (GFA) Algorithm", J Mol Biol Biotechnol 1: 1, 2016

144. Heidari, "Computational Study on Molecular Structures of C20, C60, C240, C540, C960, C2160 and C3840 Fullerene Nano Molecules under Synchrotron Radiations Using Fuzzy Logic”, J Material Sci Eng 5: 282, 2016

145. Heidari, "Graph Theoretical Analysis of Zigzag Polyhexamethylene Biguanide, Polyhexamethylene Adipamide, Polyhexamethylene Biguanide Gauze and Polyhexamethylene Biguanide Hydrochloride (PHMB) Boron Nitride Nanotubes (BNNTs), Amorphous Boron Nitride Nanotubes (a-BNNTs) and Hexagonal Boron Nitride Nanotubes (h-BNNTs)", J Appl Computat Math 5: e143, 2016

146. Heidari, "The Impact of High Resolution Imaging on Diagnosis", Int J Clin Med Imaging 3: 1000e101, 2016

147. Heidari, "A Comparative Study of Conformational Behavior of Isotretinoin (13-Cis Retinoic Acid) and Tretinoin (All-Trans Retinoic Acid (ATRA)) Nano Particles as Anti-Cancer Nano Drugs under Synchrotron Radiations Using Hartree-Fock (HF) and Density Functional Theory (DFT) Methods", Insights in Biomed 1: 2, 2016

148. Heidari, "Advances in Logic, Operations and Computational Mathematics", J Appl Computat Math 5: 5, 2016

149. Heidari, "Mathematical Equations in Predicting Physical Behavior", J Appl Computa Math 5: 5, 2016

150. Heidari, "Chemotherapy a Last Resort for Cancer Treatment", Chemo Open Access 5: 4, 2016

151. Heidari, "Separation and Pre-Concentration of Metal Cations-DNA/RNA Chelates Using Molecular Beam Mass Spectrometry with Tunable Vacuum Ultraviolet (VUV) Synchrotron Radiation and Various Analytical Methods", Mass Spectrom Purif Tech 2: e101, 2016

152. Heidari, "Yoctosecond Quantitative Structure-Activity Relationship (QSAR) and Quantitative Structure-Property Relationship (QSPR) under Synchrotron Radiations Studies for Prediction of Solubility of Anti-Cancer Nano Drugs in Aqueous Solutions Using Genetic Function Approximation (GFA) Algorithm", Insight Pharm Res 1: 1 2016

153. Heidari, "Cancer Risk Prediction and Assessment in Human Cells under Synchrotron Radiations Using Quantitative Structure Activity Relationship (QSAR) and Quantitative Structure Properties Relationship (QSPR) Studies", Int J Clin Med Imaging 3: 516, 2016

154. Heidari, “A Novel Approach to Biology”, Electronic J Biol 12: 4, 2016

155. Heidari, "Innovative Biomedical Equipment's for Diagnosis and Treatment", J Bioengineer \& Biomedical Sci 6: 2, 2016

156. Heidari, "Integrating Precision Cancer Medicine into Healthcare, Medicare Reimbursement Changes and the Practice of Oncology: Trends in Oncology Medicine and Practices", J Oncol Med \& Pract 1: 2, 2016

157. Heidari, "Promoting Convergence in Biomedical and Biomaterials Sciences and Silk Proteins for Biomedical and Biomaterials Applications: An Introduction to Materials in Medicine and Bioengineering Perspectives", J Bioengineer \& Biomedical Sci 6: 3,2016

158. Heidari, "X-Ray Fluorescence and X-Ray Diffraction Analysis on Discrete Element Modeling of Nano Powder Metallurgy Processes in Optimal Container Design", J Powder Metall Min 6: 1, 2017

159. Heidari, "Biomolecular Spectroscopy and Dynamics of Nano-Sized Molecules and Clusters as Cross-Linking-Induced Anti-Cancer and Immune-Oncology Nano Drugs Delivery in DNA/RNA of Human Cancer Cells' Membranes under Synchrotron Radiations: A Payload-Based Perspective", Arch Chem Res 1: 2, 2017

160. Heidari, "Deficiencies in Repair of Double-Standard DNA/RNA-Binding Molecules Identified in Many Types of Solid and Liquid Tumors Oncology in Human Body for Advancing Cancer Immunotherapy Using Computer Simulations and Data Analysis: Number of Mutations in a Synchronous Tumor Varies by Age and Type of Synchronous Cancer", J Appl Bioinforma Comput Biol, 6: 1, 2017

161. Heidari, "Electronic Coupling among the Five Nanomolecules Shuts Down Quantum Tunneling in the Presence and Absence of an Applied Magnetic Field for Indication of the Dimer or other Provide Different Influences on the Magnetic Behavior of Single Molecular Magnets (SMMs) as Qubits for Quantum Computing", Glob J Res Rev 4: 2, 2017

162. Heidari, "Polymorphism in Nano-Sized Graphene Ligand-Induced Transformation of $\mathrm{Au} 38-\mathrm{xAgx} / \mathrm{xCux}(\mathrm{SPh}-\mathrm{tBu}) 24$ to $\mathrm{Au} 36-\mathrm{xAgx} / \mathrm{xCux}(\mathrm{SPh}-\mathrm{tBu}) 24$ ( $\mathrm{x}=1-12)$ Nanomolecules for Synthesis of Au144-xAgx/xCux[(SR)60, (SC4)60, (SC6)60, (SC12)60, (PET)60, (p-MBA)60, (F)60, (Cl)60, (Br)60, (I)60, (At)60, (Uus)60 and (SC6H13)60] Nano Clusters as Anti-Cancer Nano Drugs", J Nanomater Mol Nanotechnol, 6: 3, 2017

163. Heidari, "Biomedical Resource Oncology and Data Mining to Enable Resource Discovery in Medical, Medicinal, Clinical, Pharmaceutical, Chemical and Translational Research and Their Applications in Cancer Research", Int J Biomed Data Min 6: e103, 2017

164. Heidari, "Study of Synthesis, Pharmacokinetics, Pharmacodynamics, Dosing, Stability, Safety and Efficacy of Olympiadane Nanomolecules as Agent for Cancer Enzymotherapy, Immunotherapy, Chemotherapy, Radiotherapy, Hormone Therapy and Targeted Therapy under Synchrotorn Radiation”, J Dev Drugs 6: e154, 2017

165. Heidari, "A Novel Approach to Future Horizon of Top Seven Biomedical Research Topics to Watch in 2017: Alzheimer's, Ebola, Hypersomnia, Human Immunodeficiency Virus (HIV), Tuberculosis (TB), Microbiome/Antibiotic Resistance and Endovascular Stroke", J Bioengineer \& Biomedical Sci 7: e127, 2017

166. Heidari, "Opinion on Computational Fluid Dynamics (CFD) Technique", Fluid Mech Open Acc 4: 157, 2017

167. Heidari, "Concurrent Diagnosis of Oncology Influence Outcomes in Emergency General Surgery for Colorectal Cancer and Multiple Sclerosis (MS) Treatment Using Magnetic Resonance Imaging (MRI) and Au329(SR)84, Au329-xAgx(SR)84, Au144(SR)60, Au68(SR)36, Au30(SR)18, Au102(SPh)44, Au38(SPh)24, Au38(SC2H4Ph)24, Au21S(SAdm)15, Au36(pMBA)24 and Au25(pMBA)18 Nano Clusters", J Surgery Emerg Med 1: 21,2017

168. Heidari, "Developmental Cell Biology in Adult Stem Cells Death and Autophagy to Trigger a Preventive Allergic Reaction to Common Airborne Allergens under Synchrotron Radiation Using Nanotechnology for Therapeutic Goals in Particular Allergy Shots (Immunotherapy)", Cell Biol (Henderson, NV) 6: 1, 2017

169. Heidari, "Changing Metal Powder Characteristics for Elimination of the Heavy Metals Toxicity and Diseases in Disruption of Extracellular Matrix (ECM) Proteins Adjustment in Cancer Metastases Induced by Osteosarcoma, Chondrosarcoma, Carcinoid, Carcinoma, Ewing's Sarcoma, Fibrosarcoma and Secondary Hematopoietic Solid or Soft Tissue Tumors", J Powder Metall Min 6: 170, 2017

170. Heidari, "Nanomedicine-Based Combination Anti-Cancer Therapy between Nucleic Acids and Anti-Cancer Nano Drugs in Covalent Nano Drugs Delivery Systems for Selective Imaging and Treatment of Human Brain Tumors Using Hyaluronic Acid, Alguronic Acid and Sodium Hyaluronate as Anti-Cancer Nano Drugs and Nucleic Acids Delivery under Synchrotron Radiation”, Am J Drug Deliv 5: 2, 2017

171. Heidari, "Clinical Trials of Dendritic Cell Therapies for Cancer Exposing Vulnerabilities in Human Cancer Cells' Metabolism and Metabolomics: New Discoveries, Unique Features Inform New Therapeutic Opportunities, Biotech's Bumpy Road to the Market and Elucidating the Biochemical Programs that Support Cancer Initiation and Progression", J Biol Med Science 1: e103, 2017

172. Heidari, "The Design Graphene-Based Nanosheets as a New Nanomaterial in AntiCancer Therapy and Delivery of Chemotherapeutics and Biological Nano Drugs for Liposomal Anti-Cancer Nano Drugs and Gene Delivery", Br Biomed Bull 5: 305, 2017

173. Heidari, "Integrative Approach to Biological Networks for Emerging Roles of Proteomics, Genomics and Transcriptomics in the Discovery and Validation of Human Colorectal Cancer Biomarkers from DNA/RNA Sequencing Data under Synchrotron Radiation", Transcriptomics 5: e117, 2017

174. Heidari, "Elimination of the Heavy Metals Toxicity and Diseases in Disruption of Extracellular Matrix (ECM) Proteins and Cell Adhesion Intelligent Nanomolecules Adjustment in Cancer Metastases Using Metalloenzymes and under Synchrotron Radiation”, Lett Health Biol Sci 2 (2): 1-4, 2017 
Heidari A (2020) Types of drug delivery system slide share of protactinium nanoparticles in human gum cancer cells, tissues and tumors treatment under synchrotron radiation

175. Heidari, "Treatment of Breast Cancer Brain Metastases through a Targeted Nanomolecule Drug Delivery System Based on Dopamine Functionalized MultiWall Carbon Nanotubes (MWCNTs) Coated with Nano Graphene Oxide (GO) and Protonated Polyaniline (PANI) in Situ During the Polymerization of Aniline Autogenic Nanoparticles for the Delivery of Anti-Cancer Nano Drugs under Synchrotron Radiation”, Br J Res, 4 (3): 16, 2017

176. Heidari, "Sedative, Analgesic and Ultrasound-Mediated Gastrointestinal Nano Drugs Delivery for Gastrointestinal Endoscopic Procedure, Nano Drug-Induced Gastrointestinal Disorders and Nano Drug Treatment of Gastric Acidity", Res Rep Gastroenterol, 1: 1, 2017

177. Heidari, "Synthesis, Pharmacokinetics, Pharmacodynamics, Dosing, Stability, Safety and Efficacy of Orphan Nano Drugs to Treat High Cholesterol and Related Conditions and to Prevent Cardiovascular Disease under Synchrotron Radiation", J Pharm Sci Emerg Drugs 5: 1, 2017

178. Heidari, "Non-Linear Compact Proton Synchrotrons to Improve Human Cancer Cells and Tissues Treatments and Diagnostics through Particle Therapy Accelerators with Monochromatic Microbeams", J Cell Biol Mol Sci 2 (1): 1-5, 2017

179. Heidari, "Design of Targeted Metal Chelation Therapeutics Nanocapsules as Colloidal Carriers and Blood-Brain Barrier (BBB) Translocation to Targeted Deliver Anti-Cancer Nano Drugs into the Human Brain to Treat Alzheimer's Disease under Synchrotron Radiation”, J Nanotechnol Material Sci 4 (2): 1-5, 2017

180. R Gobato, Heidari, "Calculations Using Quantum Chemistry for Inorganic Molecule Simulation BeLi2SeSi", Science Journal of Analytical Chemistry, Vol 5, No 6, Pages 76-85, 2017

181. Heidari, "Different High-Resolution Simulations of Medical, Medicinal, Clinical, Pharmaceutical and Therapeutics Oncology of Human Lung Cancer Translational Anti-Cancer Nano Drugs Delivery Treatment Process under Synchrotron and X-Ray Radiations", J Med Oncol Vol 1 No 1: 1, 2017

182. Heidari, "A Modern Ethnomedicinal Technique for Transformation, Prevention and Treatment of Human Malignant Gliomas Tumors into Human Benign Gliomas Tumors under Synchrotron Radiation”, Am J Ethnomed, Vol 4 No 1: 10, 2017

183. Heidari, "Active Targeted Nanoparticles for Anti-Cancer Nano Drugs Delivery across the Blood-Brain Barrier for Human Brain Cancer Treatment, Multiple Sclerosis (MS) and Alzheimer's Diseases Using Chemical Modifications of AntiCancer Nano Drugs or Drug-Nanoparticles through Zika Virus (ZIKV) Nanocarriers under Synchrotron Radiation", J Med Chem Toxicol, 2 (3): 1-5, 2017

184. Heidari, "Investigation of Medical, Medicinal, Clinical and Pharmaceutical Applications of Estradiol, Mestranol (Norlutin), Norethindrone (NET), Norethisterone Acetate (NETA), Norethisterone Enanthate (NETE) and Testosterone Nanoparticles as Biological Imaging, Cell Labeling, Anti-Microbial Agents and Anti-Cancer Nano Drugs in Nanomedicines Based Drug Delivery Systems for Anti-Cancer Targeting and Treatment", Parana Journal of Science and Education (PJSE)-v3, n4, (10-19) October 12, 2017

185. Heidari, "A Comparative Computational and Experimental Study on Different Vibrational Biospectroscopy Methods, Techniques and Applications for Human Cancer Cells in Tumor Tissues Simulation, Modeling, Research, Diagnosis and Treatment”, Open J Anal Bioanal Chem 1 (1): 014-020, 2017

186. Heidari, "Combination of DNA/RNA Ligands and Linear/Non-Linear VisibleSynchrotron Radiation-Driven N-Doped Ordered Mesoporous Cadmium Oxide (CdO) Nanoparticles Photocatalysts Channels Resulted in an Interesting Synergistic Effect Enhancing Catalytic Anti-Cancer Activity”, Enz Eng 6: 1, 2017

187. Heidari, "Modern Approaches in Designing Ferritin, Ferritin Light Chain, Transferrin, Beta-2 Transferrin and Bacterioferritin-Based Anti-Cancer Nano Drugs Encapsulating Nanosphere as DNA-Binding Proteins from Starved Cells (DPS)", Mod Appro Drug Des 1 (1) MADD000504 2017

188. Heidari, "Potency of Human Interferon $\beta-1 \mathrm{a}$ and Human Interferon $\beta-1 \mathrm{~b}$ in Enzymotherapy, Immunotherapy, Chemotherapy, Radiotherapy, Hormone Therapy and Targeted Therapy of Encephalomyelitis Disseminate/Multiple Sclerosis (MS) and Hepatitis A, B, C, D, E, F and G Virus Enter and Targets Liver Cells", J Proteomics Enzymol 6: 1, 2017

189. Heidari, "Transport Therapeutic Active Targeting of Human Brain Tumors Enable Anti-Cancer Nanodrugs Delivery across the Blood-Brain Barrier (BBB) to Treat Brain Diseases Using Nanoparticles and Nanocarriers under Synchrotron Radiation", J Pharm Pharmaceutics 4 (2): 1-5, 2017

190. Heidari, C Brown, "Combinatorial Therapeutic Approaches to DNA/RNA and Benzylpenicillin (Penicillin G), Fluoxetine Hydrochloride (Prozac and Sarafem), Propofol (Diprivan), Acetylsalicylic Acid (ASA) (Aspirin), Naproxen Sodium (Aleve and Naprosyn) and Dextromethamphetamine Nanocapsules with Surface Conjugated
DNA/RNA to Targeted Nano Drugs for Enhanced Anti-Cancer Efficacy and Targeted Cancer Therapy Using Nano Drugs Delivery Systems", Ann Adv Chem 1 (2): 061069,2017

191. Heidari, "High-Resolution Simulations of Human Brain Cancer Translational Nano Drugs Delivery Treatment Process under Synchrotron Radiation”, J Transl Res 1 (1): $1-3,2017$

192. Heidari, 'Investigation of Anti-Cancer Nano Drugs' Effects' Trend on Human Pancreas Cancer Cells and Tissues Prevention, Diagnosis and Treatment Process under Synchrotron and X-Ray Radiations with the Passage of Time Using Mathematica", Current Trends Anal Bioanal Chem, 1 (1): 36-41, 2017

193. Heidari, "Pros and Cons Controversy on Molecular Imaging and Dynamics of Double-Standard DNA/RNA of Human Preserving Stem Cells-Binding Nano Molecules with Androgens/Anabolic Steroids (AAS) or Testosterone Derivatives through Tracking of Helium-4 Nucleus (Alpha Particle) Using Synchrotron Radiation”, Arch Biotechnol Biomed 1 (1): 067-0100, 2017

194. Heidari, "Visualizing Metabolic Changes in Probing Human Cancer Cells and Tissues Metabolism Using Vivo 1H or Proton NMR, 13C NMR, 15N NMR and 31P NMR Spectroscopy and Self-Organizing Maps under Synchrotron Radiation”, SOJ Mater Sci Eng 5 (2): 1-6, 2017

195. Heidari, “Cavity Ring-Down Spectroscopy (CRDS), Circular Dichroism Spectroscopy, Cold Vapour Atomic Fluorescence Spectroscopy and Correlation Spectroscopy Comparative Study on Malignant and Benign Human Cancer Cells and Tissues with the Passage of Time under Synchrotron Radiation”, Enliven: Challenges Cancer Detect Ther 4 (2): e001, 2017

196. Heidari, "Laser Spectroscopy, Laser-Induced Breakdown Spectroscopy and LaserInduced Plasma Spectroscopy Comparative Study on Malignant and Benign Human Cancer Cells and Tissues with the Passage of Time under Synchrotron Radiation", Int J Hepatol Gastroenterol, 3 (4): 079-084, 2017

197. Heidari, "Time-Resolved Spectroscopy and Time-Stretch Spectroscopy Comparative Study on Malignant and Benign Human Cancer Cells and Tissues with the Passage of Time under Synchrotron Radiation", Enliven: Pharmacovigilance and Drug Safety 4 (2): e001, 2017

198. Heidari, "Overview of the Role of Vitamins in Reducing Negative Effect of Decapeptyl (Triptorelin Acetate or Pamoate Salts) on Prostate Cancer Cells and Tissues in Prostate Cancer Treatment Process through Transformation of Malignant Prostate Tumors into Benign Prostate Tumors under Synchrotron Radiation”, Open J Anal Bioanal Chem 1 (1): 021-026, 2017

199. Heidari, "Electron Phenomenological Spectroscopy, Electron Paramagnetic Resonance (EPR) Spectroscopy and Electron Spin Resonance (ESR) Spectroscopy Comparative Study on Malignant and Benign Human Cancer Cells and Tissues with the Passage of Time under Synchrotron Radiation", Austin J Anal Pharm Chem 4 (3): 1091, 2017

200. Heidari, "Therapeutic Nanomedicine Different High-Resolution Experimental Images and Computational Simulations for Human Brain Cancer Cells and Tissues Using Nanocarriers Deliver DNA/RNA to Brain Tumors under Synchrotron Radiation with the Passage of Time Using Mathematica and MATLAB", Madridge J Nano Tech Sci 2 (2): 77-83, 2017

201. Heidari, "A Consensus and Prospective Study on Restoring Cadmium Oxide (CdO) Nanoparticles Sensitivity in Recurrent Ovarian Cancer by Extending the Cadmium Oxide (CdO) Nanoparticles-Free Interval Using Synchrotron Radiation Therapy as Antibody-Drug Conjugate for the Treatment of Limited-Stage Small Cell Diverse Epithelial Cancers", Cancer Clin Res Rep, 1: 2, e001, 2017

202. Heidari, "A Novel and Modern Experimental Imaging and Spectroscopy Comparative Study on Malignant and Benign Human Cancer Cells and Tissues with the Passage of Time under White Synchrotron Radiation”, Cancer Sci Res Open Access 4 (2): $1-8,2017$

203. Heidari, "Different High-Resolution Simulations of Medical, Medicinal, Clinical, Pharmaceutical and Therapeutics Oncology of Human Breast Cancer Translational Nano Drugs Delivery Treatment Process under Synchrotron and X-Ray Radiations", J Oral Cancer Res 1 (1): 12-17, 2017

204. Heidari, "Vibrational Decihertz (dHz), Centihertz (cHz), Millihertz (mHz), Microhertz $(\mu \mathrm{Hz})$, Nanohertz (nHz), Picohertz (pHz), Femtohertz (fHz), Attohertz $(\mathrm{aHz})$, Zeptohertz $(\mathrm{zHz})$ and Yoctohertz $(\mathrm{yHz})$ Imaging and Spectroscopy Comparative Study on Malignant and Benign Human Cancer Cells and Tissues under Synchrotron Radiation”, International Journal of Biomedicine, 7 (4), 335-340, 2017

205. Heidari, "Force Spectroscopy and Fluorescence Spectroscopy Comparative Study on Malignant and Benign Human Cancer Cells and Tissues with the Passage of Time under Synchrotron Radiation”, EC Cancer, 2 (5), 239-246, 2017 
Heidari A (2020) Types of drug delivery system slide share of protactinium nanoparticles in human gum cancer cells, tissues and tumors treatment under synchrotron radiation

206. Heidari, "Photoacoustic Spectroscopy, Photoemission Spectroscopy and Photothermal Spectroscopy Comparative Study on Malignant and Benign Human Cancer Cells and Tissues with the Passage of Time under Synchrotron Radiation", BAOJ Cancer Res Ther, 3: 3, 045-052, 2017

207. Heidari, "J-Spectroscopy, Exchange Spectroscopy (EXSY), Nuclear Overhauser Effect Spectroscopy (NOESY) and Total Correlation Spectroscopy (TOCSY) Comparative Study on Malignant and Benign Human Cancer Cells and Tissues under Synchrotron Radiation", EMS Eng Sci J, 1 (2): 006-013, 2017

208. Heidari, "Neutron Spin Echo Spectroscopy and Spin Noise Spectroscopy Comparative Study on Malignant and Benign Human Cancer Cells and Tissues with the Passage of Time under Synchrotron Radiation”, Int J Biopharm Sci, 1: 103-107, 2017

209. Heidari, "Vibrational Decahertz (daHz), Hectohertz (hHz), Kilohertz (kHz), Megahertz (MHz), Gigahertz (GHz), Terahertz (THz), Petahertz (PHz), Exahertz $(\mathrm{EHz})$, Zettahertz $(\mathrm{ZHz})$ and Yottahertz $(\mathrm{YHz})$ Imaging and Spectroscopy Comparative Study on Malignant and Benign Human Cancer Cells and Tissues under Synchrotron Radiation”, Madridge J Anal Sci Instrum, 2 (1): 41-46, 2017

210. Heidari, "Two-Dimensional Infrared Correlation Spectroscopy, Linear TwoDimensional Infrared Spectroscopy and Non-Linear Two-Dimensional Infrared Spectroscopy Comparative Study on Malignant and Benign Human Cancer Cells and Tissues under Synchrotron Radiation with the Passage of Time”, J Mater Sci Nanotechnol 6 (1): 101, 2018

211. Heidari, "Fourier Transform Infrared (FTIR) Spectroscopy, Near-Infrared Spectroscopy (NIRS) and Mid-Infrared Spectroscopy (MIRS) Comparative Study on Malignant and Benign Human Cancer Cells and Tissues under Synchrotron Radiation with the Passage of Time", Int J Nanotechnol Nanomed, Volume 3, Issue 1, Pages $1-6,2018$

212. Heidari, "Infrared Photo Dissociation Spectroscopy and Infrared Correlation Table Spectroscopy Comparative Study on Malignant and Benign Human Cancer Cells and Tissues under Synchrotron Radiation with the Passage of Time", Austin Pharmacol Pharm, 3 (1): 1011, 2018

213. Heidari, "Novel and Transcendental Prevention, Diagnosis and Treatment Strategies for Investigation of Interaction among Human Blood Cancer Cells, Tissues, Tumors and Metastases with Synchrotron Radiation under Anti-Cancer Nano Drugs Delivery Efficacy Using MATLAB Modeling and Simulation", Madridge J Nov Drug Res, 1 (1): $18-24,2017$

214. Heidari, "Comparative Study on Malignant and Benign Human Cancer Cells and Tissues with the Passage of Time under Synchrotron Radiation", Open Access J Trans Med Res, 2 (1): 00026-00032, 2018

215. M R R Gobato, R Gobato, Heidari, "Planting of Jaboticaba Trees for Landscape Repair of Degraded Area", Landscape Architecture and Regional Planning, Vol 3, No 1, 2018, Pages 1-9, 2018

216. Heidari, "Fluorescence Spectroscopy, Phosphorescence Spectroscopy and Luminescence Spectroscopy Comparative Study on Malignant and Benign Human Cancer Cells and Tissues under Synchrotron Radiation with the Passage of Time", SM J Clin Med Imaging, 4 (1): 1018, 2018

217. Heidari, "Nuclear Inelastic Scattering Spectroscopy (NISS) and Nuclear Inelastic Absorption Spectroscopy (NIAS) Comparative Study on Malignant and Benign Human Cancer Cells and Tissues under Synchrotron Radiation”, Int J Pharm Sci, 2 (1): $1-14,2018$

218. Heidari, "X-Ray Diffraction (XRD), Powder X-Ray Diffraction (PXRD) and Energy-Dispersive X-Ray Diffraction (EDXRD) Comparative Study on Malignan and Benign Human Cancer Cells and Tissues under Synchrotron Radiation", J Oncol Res; 2 (1): 1-14, 2018

219. Heidari, "Correlation Two-Dimensional Nuclear Magnetic Resonance (NMR) (2DNMR) (COSY) Imaging and Spectroscopy Comparative Study on Malignant and Benign Human Cancer Cells and Tissues under Synchrotron Radiation", EMS Can Sci, 1-1-001, 2018

220. Heidari, "Thermal Spectroscopy, Photothermal Spectroscopy, Thermal Microspectroscopy, Photothermal Microspectroscopy, Thermal Macrospectroscopy and Photothermal Macrospectroscopy Comparative Study on Malignant and Benign Human Cancer Cells and Tissues with the Passage of Time under Synchrotron Radiation”, SM J Biometrics Biostat, 3 (1): 1024, 2018

221. Heidari, "A Modern and Comprehensive Experimental Biospectroscopic Comparative Study on Human Common Cancers' Cells, Tissues and Tumors before and after Synchrotron Radiation Therapy”, Open Acc J Oncol Med 1 (1), 2018

222. Heidari, "Heteronuclear Correlation Experiments such as Heteronuclear SingleQuantum Correlation Spectroscopy (HSQC), Heteronuclear Multiple-Quantum Correlation Spectroscopy (HMQC) and Heteronuclear Multiple-Bond Correlation Spectroscopy (HMBC) Comparative Study on Malignant and Benign Human
Endocrinology and Thyroid Cancer Cells and Tissues under Synchrotron Radiation", J Endocrinol Thyroid Res, 3 (1): 555603, 2018

223. Heidari, "Nuclear Resonance Vibrational Spectroscopy (NRVS), Nuclear Inelastic Scattering Spectroscopy (NISS), Nuclear Inelastic Absorption Spectroscopy (NIAS) and Nuclear Resonant Inelastic X-Ray Scattering Spectroscopy (NRIXSS) Comparative Study on Malignant and Benign Human Cancer Cells and Tissues under Synchrotron Radiation”, Int J Bioorg Chem Mol Biol 6 (1e): 1-5, 2018

224. Heidari, "A Novel and Modern Experimental Approach to Vibrational Circular Dichroism Spectroscopy and Video Spectroscopy Comparative Study on Malignant and Benign Human Cancer Cells and Tissues with the Passage of Time under White and Monochromatic Synchrotron Radiation”, Glob J Endocrinol Metab 1 (3) GJEM 000514-000519, 2018

225. Heidari, "Pros and Cons Controversy on Heteronuclear Correlation Experiments such as Heteronuclear Single-Quantum Correlation Spectroscopy (HSQC), Heteronuclear Multiple-Quantum Correlation Spectroscopy (HMQC) and Heteronuclear MultipleBond Correlation Spectroscopy (HMBC) Comparative Study on Malignant and Benign Human Cancer Cells and Tissues under Synchrotron Radiation”, EMS Pharma J 1 (1): 002-008, 2018

226. Heidari, “A Modern Comparative and Comprehensive Experimental Biospectroscopic Study on Different Types of Infrared Spectroscopy of Malignant and Benign Human Cancer Cells and Tissues with the Passage of Time under Synchrotron Radiation”, J Analyt Molecul Tech 3 (1): 8, 2018

227. Heidari, "Investigation of Cancer Types Using Synchrotron Technology for Proton Beam Therapy: An Experimental Biospectroscopic Comparative Study", European Modern Studies Journal, Vol 2, No 1, 13-29, 2018

228. Heidari, "Saturated Spectroscopy and Unsaturated Spectroscopy Comparative Study on Malignant and Benign Human Cancer Cells and Tissues with the Passage of Time under Synchrotron Radiation”, Imaging J Clin Medical Sci 5 (1): 001-007, 2018

229. Heidari, "Small-Angle Neutron Scattering (SANS) and Wide-Angle X-Ray Diffraction (WAXD) Comparative Study on Malignant and Benign Human Cancer Cells and Tissues under Synchrotron Radiation", Int J Bioorg Chem Mol Biol 6 (2e): $1-6,2018$

230. Heidari, "Investigation of Bladder Cancer, Breast Cancer, Colorectal Cancer, Endometrial Cancer, Kidney Cancer, Leukemia, Liver, Lung Cancer, Melanoma, Non-Hodgkin Lymphoma, Pancreatic Cancer, Prostate Cancer, Thyroid Cancer and Non-Melanoma Skin Cancer Using Synchrotron Technology for Proton Beam Therapy: An Experimental Biospectroscopic Comparative Study", Ther Res Skin Dis $1(1), 2018$

231. Heidari, "Attenuated Total Reflectance Fourier Transform Infrared (ATR-FTIR) Spectroscopy, Micro-Attenuated Total Reflectance Fourier Transform Infrared (Micro-ATR-FTIR) Spectroscopy and Macro-Attenuated Total Reflectance Fourier Transform Infrared (Macro-ATR-FTIR) Spectroscopy Comparative Study on Malignant and Benign Human Cancer Cells and Tissues under Synchrotron Radiation with the Passage of Time", International Journal of Chemistry Papers, 2 (1): 1-12, 2018

232. Heidari, "Mössbauer Spectroscopy, Mössbauer Emission Spectroscopy and 57Fe Mössbauer Spectroscopy Comparative Study on Malignant and Benign Human Cancer Cells and Tissues under Synchrotron Radiation", Acta Scientific Cancer Biology 23: 17-20, 2018

233. Heidari, "Comparative Study on Malignant and Benign Human Cancer Cells and Tissues under Synchrotron Radiation with the Passage of Time", Organic \& Medicinal Chem IJ 6 (1): 555676, 2018

234. Heidari, "Correlation Spectroscopy, Exclusive Correlation Spectroscopy and Total Correlation Spectroscopy Comparative Study on Malignant and Benign Human AIDS-Related Cancers Cells and Tissues with the Passage of Time under Synchrotron Radiation", Int J Bioanal Biomed 2 (1): 001-007, 2018

235. Heidari, "Biomedical Instrumentation and Applications of Biospectroscopic Methods and Techniques in Malignant and Benign Human Cancer Cells and Tissues Studies under Synchrotron Radiation and Anti-Cancer Nano Drugs Delivery", Am J Nanotechnol Nanomed 1 (1): 001-009, 2018

236. Heidari, "Vivo $1 \mathrm{H}$ or Proton NMR, 13C NMR, 15N NMR and 31P NMR Spectroscopy Comparative Study on Malignant and Benign Human Cancer Cells and Tissues under Synchrotron Radiation”, Ann Biomet Biostat 1 (1): 1001, 2018

237. Heidari, "Grazing-Incidence Small-Angle Neutron Scattering (GISANS) and Grazing-Incidence X-Ray Diffraction (GIXD) Comparative Study on Malignant and Benign Human Cancer Cells, Tissues and Tumors under Synchrotron Radiation", Ann Cardiovasc Surg 1 (2): 1006, 2018 
Heidari A (2020) Types of drug delivery system slide share of protactinium nanoparticles in human gum cancer cells, tissues and tumors treatment under synchrotron radiation

238. Heidari, "Adsorption Isotherms and Kinetics of Multi-Walled Carbon Nanotubes (MWCNTs), Boron Nitride Nanotubes (BNNTs), Amorphous Boron Nitride Nanotubes (a-BNNTs) and Hexagonal Boron Nitride Nanotubes (h-BNNTs) for Eliminating Carcinoma, Sarcoma, Lymphoma, Leukemia, Germ Cell Tumor and Blastoma Cancer Cells and Tissues", Clin Med Rev Case Rep 5: 201, 2018

239. Heidari, "Correlation Spectroscopy (COSY), Exclusive Correlation Spectroscopy (ECOSY), Total Correlation Spectroscopy (TOCSY), Incredible Natural-Abundance Double-Quantum Transfer Experiment (INADEQUATE), Heteronuclear SingleQuantum Correlation Spectroscopy (HSQC), Heteronuclear Multiple-Bond Correlation Spectroscopy (HMBC), Nuclear Overhauser Effect Spectroscopy (NOESY) and Rotating Frame Nuclear Overhauser Effect Spectroscopy (ROESY) Comparative Study on Malignant and Benign Human Cancer Cells and Tissues under Synchrotron Radiation", Acta Scientific Pharmaceutical Sciences 25: 30-35, 2018

240. Heidari, "Small-Angle X-Ray Scattering (SAXS), Ultra-Small Angle X-Ray Scattering (USAXS), Fluctuation X-Ray Scattering (FXS), Wide-Angle X-Ray Scattering (WAXS), Grazing-Incidence Small-Angle X-Ray Scattering (GISAXS), Grazing-Incidence Wide-Angle X-Ray Scattering (GIWAXS), Small-Angle Neutron Scattering (SANS), Grazing-Incidence Small-Angle Neutron Scattering (GISANS), X-Ray Diffraction (XRD), Powder X-Ray Diffraction (PXRD), Wide-Angle X-Ray Diffraction (WAXD), Grazing-Incidence X-Ray Diffraction (GIXD) and Energy-Dispersive X-Ray Diffraction (EDXRD) Comparative Study on Malignant and Benign Human Cancer Cells and Tissues under Synchrotron Radiation", Oncol Res Rev, Volume 1 (1): 1-10, 2018

241. Heidari, "Pump-Probe Spectroscopy and Transient Grating Spectroscopy Comparative Study on Malignant and Benign Human Cancer Cells and Tissues with the Passage of Time under Synchrotron Radiation", Adv Material Sci Engg, Volume 2, Issue 1, Pages 1-7, 2018

242. Heidari, "Grazing-Incidence Small-Angle X-Ray Scattering (GISAXS) and Grazing-Incidence Wide-Angle X-Ray Scattering (GIWAXS) Comparative Study on Malignant and Benign Human Cancer Cells and Tissues under Synchrotron Radiation", Insights Pharmacol Pharm Sci 1 (1): 1-8, 2018

243. Heidari, "Acoustic Spectroscopy, Acoustic Resonance Spectroscopy and Auger Spectroscopy Comparative Study on Anti-Cancer Nano Drugs Delivery in Malignant and Benign Human Cancer Cells and Tissues with the Passage of Time under Synchrotron Radiation", Nanosci Technol 5 (1): 1-9, 2018

244. Heidari, "Niobium, Technetium, Ruthenium, Rhodium, Hafnium, Rhenium, Osmium and Iridium Ions Incorporation into the Nano Polymeric Matrix (NPM) by Immersion of the Nano Polymeric Modified Electrode (NPME) as Molecular Enzymes and Drug Targets for Human Cancer Cells, Tissues and Tumors Treatment under Synchrotron and Synchrocyclotron Radiations", Nanomed Nanotechnol, 3 (2): 000138, 2018

245. Heidari, "Homonuclear Correlation Experiments such as Homonuclear SingleQuantum Correlation Spectroscopy (HSQC), Homonuclear Multiple-Quantum Correlation Spectroscopy (HMQC) and Homonuclear Multiple-Bond Correlation Spectroscopy (HMBC) Comparative Study on Malignant and Benign Human Cancer Cells and Tissues under Synchrotron Radiation", Austin J Proteomics Bioinform \& Genomics 5 (1): 1024, 2018

246. Heidari, "Atomic Force Microscopy Based Infrared (AFM-IR) Spectroscopy and Nuclear Resonance Vibrational Spectroscopy Comparative Study on Malignant and Benign Human Cancer Cells and Tissues under Synchrotron Radiation with the Passage of Time", J Appl Biotechnol Bioeng 5 (3): 142-148, 2018

247. Heidari, "Time-Dependent Vibrational Spectral Analysis of Malignant and Benign Human Cancer Cells and Tissues under Synchrotron Radiation", J Cancer Oncol, 2 (2): 000124, 2018

248. Heidari, "Palauamine and Olympiadane Nano Molecules Incorporation into the Nano Polymeric Matrix (NPM) by Immersion of the Nano Polymeric Modified Electrode (NPME) as Molecular Enzymes and Drug Targets for Human Cancer Cells, Tissues and Tumors Treatment under Synchrotron and Synchrocyclotron Radiations", Arc Org Inorg Chem Sci 3 (1), 2018

249. R Gobato, Heidari, "Infrared Spectrum and Sites of Action of Sanguinarine by Molecular Mechanics and ab initio Methods", International Journal of Atmospheric and Oceanic Sciences Vol 2, No 1, pp 1-9, 2018

250. Heidari, “Angelic Acid, Diabolic Acids, Draculin and Miraculin Nano Molecules Incorporation into the Nano Polymeric Matrix (NPM) by Immersion of the Nano Polymeric Modified Electrode (NPME) as Molecular Enzymes and Drug Targets for Human Cancer Cells, Tissues and Tumors Treatment Under Synchrotron and Synchrocyclotron Radiations", Med \& Analy Chem Int J, 2 (1): 000111, 2018

251. Heidari, "Gamma Linolenic Methyl Ester, 5-Heptadeca-5,8,11-Trienyl 1,3,4 Oxadiazole-2-Thiol, Sulphoquinovosyl Diacyl Glycerol, Ruscogenin, Nocturnoside B, Protodioscine B, Parquisoside-B, Leiocarposide, Narangenin, 7-Methoxy
Hespertin, Lupeol, Rosemariquinone, Rosmanol and Rosemadiol Nano Molecules Incorporation into the Nano Polymeric Matrix (NPM) by Immersion of the Nano Polymeric Modified Electrode (NPME) as Molecular Enzymes and Drug Targets for Human Cancer Cells, Tissues and Tumors Treatment under Synchrotron and Synchrocyclotron Radiations", Int J Pharma Anal Acta, 2 (1): 007-014, 2018

252. Heidari, "Fourier Transform Infrared (FTIR) Spectroscopy, Attenuated Total Reflectance Fourier Transform Infrared(ATR-FTIR) Spectroscopy, Micro-Attenuated Total Reflectance Fourier Transform Infrared (Micro-ATR-FTIR) Spectroscopy, Macro-Attenuated Total Reflectance Fourier Transform Infrared (Macro-ATRFTIR) Spectroscopy, Two-Dimensional Infrared Correlation Spectroscopy, Linear Two-Dimensional Infrared Spectroscopy, Non-Linear Two-Dimensional Infrared Spectroscopy, Atomic Force Microscopy Based Infrared (AFM-IR) Spectroscopy, Infrared Photodissociation Spectroscopy, Infrared Correlation Table Spectroscopy, Near-Infrared Spectroscopy (NIRS), Mid-Infrared Spectroscopy (MIRS), Nuclear Resonance Vibrational Spectroscopy, Thermal Infrared Spectroscopy and Photothermal Infrared Spectroscopy Comparative Study on Malignant and Benign Human Cancer Cells and Tissues under Synchrotron Radiation with the Passage of Time”, Glob Imaging Insights, Volume 3 (2): 1-14, 2018

253. Heidari, "Heteronuclear Single-Quantum Correlation Spectroscopy (HSQC) and Heteronuclear Multiple-Bond Correlation Spectroscopy (HMBC) Comparative Study on Malignant and Benign Human Cancer Cells, Tissues and Tumors under Synchrotron and Synchrocyclotron Radiations", Chronicle of Medicine and Surgery 23: $144-156,2018$

254. Heidari, "Tetrakis [3, 5-bis (Trifluoromethyl) Phenyl] Borate (BARF)-Enhanced Precatalyst Preparation Stabilization and Initiation (EPPSI) Nano Molecules", Medical Research and Clinical Case Reports 21: 113-126, 2018

255. Heidari, "Sydnone, Münchnone, Montréalone, Mogone, Montelukast, Quebecol and Palau'amine-Enhanced Precatalyst Preparation Stabilization and Initiation (EPPSI) Nano Molecules", Sur Cas Stud Op Acc J 1 (3), 2018

256. Heidari, "Fornacite, Orotic Acid, Rhamnetin, Sodium Ethyl Xanthate (SEX) and Spermine (Spermidine or Polyamine) Nanomolecules Incorporation into the Nanopolymeric Matrix (NPM)", International Journal of Biochemistry and Biomolecules, Vol 4: Issue 1, Pages 1-19, 2018

257. Heidari, R Gobato, "Putrescine, Cadaverine, Spermine and Spermidine-Enhanced Precatalyst Preparation Stabilization and Initiation (EPPSI) Nano Molecules", Parana Journal of Science and Education (PJSE)-v4, n5, (1-14) July 1, 2018

258. Heidari, "Cadaverine (1,5-Pentanediamine or Pentamethylenediamine), Diethyl Azodicarboxylate (DEAD or DEADCAT) and Putrescine (Tetramethylenediamine) Nano Molecules Incorporation into the Nano Polymeric Matrix (NPM) by Immersion of the Nano Polymeric Modified Electrode (NPME) as Molecular Enzymes and Drug Targets for Human Cancer Cells, Tissues and Tumors Treatment under Synchrotron and Synchrocyclotron Radiations", Hiv and Sexual Health Open Access Open Journal 1 (1): 4-11, 2018

259. Heidari, "Improving the Performance of Nano-Endofullerenes in Polyaniline Nanostructure-Based Biosensors by Covering Californium Colloidal Nanoparticles with Multi-Walled Carbon Nanotubes", Journal of Advances in Nanomaterials, Vol 3, No 1, Pages 1-28, 2018

260. R Gobato, Heidari, "Molecular Mechanics and Quantum Chemical Study on Sites of Action of Sanguinarine Using Vibrational Spectroscopy Based on Molecular Mechanics and Quantum Chemical Calculations", Malaysian Journal of Chemistry, Vol 20 (1), 1-23, 2018

261. Heidari, "Vibrational Biospectroscopic Studies on Anti-cancer Nanopharmaceuticals (Part I)”, Malaysian Journal of Chemistry, Vol 20 (1), 33-73, 2018

262. Heidari, "Vibrational Biospectroscopic Studies on Anti-cancer Nanopharmaceuticals (Part II)", Malaysian Journal of Chemistry, Vol 20 (1), 74-117, 2018

263. Heidari, "Uranocene $(\mathrm{U}(\mathrm{C} 8 \mathrm{H} 8) 2)$ and Bis(Cyclooctatetraene)Iron $(\mathrm{Fe}(\mathrm{C} 8 \mathrm{H} 8) 2$ or $\mathrm{Fe}(\mathrm{COT}) 2$ )-Enhanced Precatalyst Preparation Stabilization and Initiation (EPPSI) Nano Molecules", Chemistry Reports, Vol 1, Iss 2, Pages 1-16, 2018

264. Heidari, "Biomedical Systematic and Emerging Technological Study on Human Malignant and Benign Cancer Cells and Tissues Biospectroscopic Analysis under Synchrotron Radiation", Glob Imaging Insights, Volume 3 (3): 1-7, 2018

265. Heidari, "Deep-Level Transient Spectroscopy and X-Ray Photoelectron Spectroscopy (XPS) Comparative Study on Malignant and Benign Human Cancer Cells and Tissues with the Passage of Time under Synchrotron Radiation", Res Dev Material Sci 7(2) RDMS000659, 2018

266. Heidari, "C70-Carboxyfullerenes Nano Molecules Incorporation into the Nano Polymeric Matrix (NPM) by Immersion of the Nano Polymeric Modified Electrode (NPME) as Molecular Enzymes and Drug Targets for Human Cancer Cells, Tissues 
Heidari A (2020) Types of drug delivery system slide share of protactinium nanoparticles in human gum cancer cells, tissues and tumors treatment under synchrotron radiation

and Tumors Treatment under Synchrotron and Synchrocyclotron Radiations", Glob Imaging Insights, Volume 3 (3): 1-7, 2018

267. Heidari, "The Effect of Temperature on Cadmium Oxide (CdO) Nanoparticles Produced by Synchrotron Radiation in the Human Cancer Cells, Tissues and Tumors", International Journal of Advanced Chemistry, 6 (2) 140-156, 2018

268. Heidari, "A Clinical and Molecular Pathology Investigation of Correlation Spectroscopy (COSY), Exclusive Correlation Spectroscopy (ECOSY), Total Correlation Spectroscopy (TOCSY), Heteronuclear Single-Quantum Correlation Spectroscopy (HSQC) and Heteronuclear Multiple-Bond Correlation Spectroscopy (HMBC) Comparative Study on Malignant and Benign Human Cancer Cells, Tissues and Tumors under Synchrotron and Synchrocyclotron Radiations Using Cyclotron versus Synchrotron, Synchrocyclotron and the Large Hadron Collider (LHC) for Delivery of Proton and Helium Ion (Charged Particle) Beams for Oncology Radiotherapy", European Journal of Advances in Engineering and Technology, 5 (7) 414-426, 2018

269. Heidari, "Nano Molecules Incorporation into the Nano Polymeric Matrix (NPM) by Immersion of the Nano Polymeric Modified Electrode (NPME) as Molecular Enzymes and Drug Targets for Human Cancer Cells, Tissues and Tumors Treatment under Synchrotron and Synchrocyclotron Radiations", J Oncol Res; 1 (1): 1-20, 2018

270. Heidari, "Use of Molecular Enzymes in the Treatment of Chronic Disorders", Canc Oncol Open Access J 1 (1): 12-15, 2018

271. Heidari, "Vibrational Biospectroscopic Study and Chemical Structure Analysis of Unsaturated Polyamides Nanoparticles as Anti-Cancer Polymeric Nanomedicines Using Synchrotron Radiation”, International Journal of Advanced Chemistry, 6 (2), $167-189,2018$

272. Heidari, "Adamantane, Irene, Naftazone and Pyridine-Enhanced Precatalyst Preparation Stabilization and Initiation (PEPPSI) Nano Molecules", Madridge J Nov Drug Res 2 (1): 61-67, 2018

273. Heidari, "Heteronuclear Single-Quantum Correlation Spectroscopy (HSQC) and Heteronuclear Multiple-Bond Correlation Spectroscopy (HMBC) Comparative Study on Malignant and Benign Human Cancer Cells and Tissues with the Passage of Time under Synchrotron Radiation”, Madridge J Nov Drug Res, 2 (1): 68-74, 2018

274. Heidari, R Gobato, "A Novel Approach to Reduce Toxicities and to Improve Bioavailabilities of DNA/RNA of Human Cancer Cells-Containing Cocaine (Coke), Lysergide (Lysergic Acid Diethyl Amide or LSD), $\Delta^{9}$-Tetrahydrocannabinol (THC) [(-)-trans $-\Delta^{9}-$ Tetrahydrocannabinol], Theobromine (Xantheose), Caffeine, Aspartame (APM) (NutraSweet) and Zidovudine (ZDV) [Azidothymidine (AZT)] as Anti-Cancer Nano Drugs by Coassembly of Dual Anti-Cancer Nano Drugs to Inhibit DNA/RNA of Human Cancer Cells Drug Resistance", Parana Journal of Science and Education, v 4, n 6, pp 1-17, 2018

275. Heidari, R Gobato, "Ultraviolet Photoelectron Spectroscopy (UPS) and UltravioletVisible (UV-Vis) Spectroscopy Comparative Study on Malignant and Benign Human Cancer Cells and Tissues with the Passage of Time under Synchrotron Radiation", Parana Journal of Science and Education, v 4, n 6, pp 18-33, 2018

276. R Gobato, Heidari, Mitra, "The Creation of C13H20BeLi2SeSi The Proposal of a Bio-Inorganic Molecule, Using Ab Initio Methods for the Genesis of a Nano Membrane", Arc Org Inorg Chem Sci 3 (4) AOICSMSID000167, 2018

277. R Gobato, Heidari, Mitra, "Using the Quantum Chemistry for Genesis of a Nano Biomembrane with a Combination of the Elements $\mathrm{Be}, \mathrm{Li}, \mathrm{Se}, \mathrm{Si}, \mathrm{C}$ and H", ResearchGate, See discussions, stats, and author profiles for this publication at: https://wwwresearchgatenet/publication/326201181, 2018

278. R Gobato, Heidari, "Using the Quantum Chemistry for Genesis of a Nano Biomembrane with a Combination of the Elements $\mathrm{Be}, \mathrm{Li}, \mathrm{Se}, \mathrm{Si}, \mathrm{C}$ and $\mathrm{H}$ ", J Nanomed Res7 (4): 241-252, 2018

279. Heidari, "Bastadins and Bastaranes-Enhanced Precatalyst Preparation Stabilization and Initiation (EPPSI) Nano Molecules", Glob Imaging Insights, Volume 3 (4): 1-7, 2018

280. Heidari, "Fucitol, Pterodactyladiene, DEAD or DEADCAT (DiEthyl AzoDiCArboxylaTe), Skatole, the NanoPutians, Thebacon, Pikachurin, Tie Fighter, Spermidine and Mirasorvone Nano Molecules Incorporation into the Nano Polymeric Matrix (NPM) by Immersion of the Nano Polymeric Modified Electrode (NPME) as Molecular Enzymes and Drug Targets for Human Cancer Cells, Tissues and Tumors Treatment under Synchrotron and Synchrocyclotron Radiations", Glob Imaging Insights, Volume 3 (4): 1-8, 2018

281. E Dadvar, Heidari, “A Review on Separation Techniques of Graphene Oxide (GO)/ Base on Hybrid Polymer Membranes for Eradication of Dyes and Oil Compounds: Recent Progress in Graphene Oxide (GO)/Base on Polymer Membranes-Related Nanotechnologies", Clin Med Rev Case Rep 5: 228, 2018
282. Heidari, R Gobato, "First-Time Simulation of Deoxyuridine Monophosphate (dUMP) (Deoxyuridylic Acid or Deoxyuridylate) and Vomitoxin (Deoxynivalenol

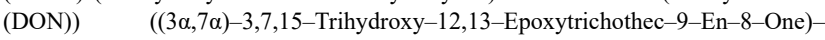
Enhanced Precatalyst Preparation Stabilization and Initiation (EPPSI) Nano Molecules Incorporation into the Nano Polymeric Matrix (NPM) by Immersion of the Nano Polymeric Modified Electrode (NPME) as Molecular Enzymes and Drug Targets for Human Cancer Cells, Tissues and Tumors Treatment under Synchrotron and Synchrocyclotron Radiations", Parana Journal of Science and Education, Vol 4 , No 6, pp 46-67, 2018

283. Heidari, "Buckminsterfullerene (Fullerene), Bullvalene, Dickite and Josiphos Ligands Nano Molecules Incorporation into the Nano Polymeric Matrix (NPM) by Immersion of the Nano Polymeric Modified Electrode (NPME) as Molecular Enzymes and Drug Targets for Human Hematology and Thromboembolic Diseases Prevention, Diagnosis and Treatment under Synchrotron and Synchrocyclotron Radiations", Glob Imaging Insights, Volume 3 (4): 1-7, 2018

284. Heidari, "Fluctuation X-Ray Scattering (FXS) and Wide-Angle X-Ray Scattering (WAXS) Comparative Study on Malignant and Benign Human Cancer Cells and Tissues under Synchrotron Radiation", Glob Imaging Insights, Volume 3 (4): 1-7, 2018

285. Heidari, "A Novel Approach to Correlation Spectroscopy (COSY), Exclusive Correlation Spectroscopy (ECOSY), Total Correlation Spectroscopy (TOCSY), Incredible Natural-Abundance Double-Quantum Transfer Experiment (INADEQUATE), Heteronuclear Single-Quantum Correlation Spectroscopy (HSQC), Heteronuclear Multiple-Bond Correlation Spectroscopy (HMBC), Nuclear Overhauser Effect Spectroscopy (NOESY) and Rotating Frame Nuclear Overhauser Effect Spectroscopy (ROESY) Comparative Study on Malignant and Benign Human Cancer Cells and Tissues under Synchrotron Radiation”, Glob Imaging Insights, Volume 3 (5): 1-9, 2018

286. Heidari, "Terphenyl-Based Reversible Receptor with Rhodamine, RhodamineBased Molecular Probe, Rhodamine-Based Using the Spirolactam Ring Opening, Rhodamine B with Ferrocene Substituent, CalixArene-Based Receptor, Thioether + Aniline-Derived Ligand Framework Linked to a Fluorescein Platform, Mercuryfluor-1 (Flourescent Probe), N,N'-Dibenzyl-1,4,10,13-Tetraraoxa-7,16Diazacyclooctadecane and Terphenyl-Based Reversible Receptor with Pyrene and Quinoline as the Fluorophores-Enhanced Precatalyst Preparation Stabilization and Initiation (EPPSI) Nano Molecules", Glob Imaging Insights, Volume 3 (5): 1-9, 2018

287. Heidari, "Small-Angle X-Ray Scattering (SAXS), Ultra-Small Angle X-Ray Scattering (USAXS), Fluctuation X-Ray Scattering (FXS), Wide-Angle X-Ray Scattering (WAXS), Grazing-Incidence Small-Angle X-Ray Scattering (GISAXS), Grazing-Incidence Wide-Angle X-Ray Scattering (GIWAXS), Small-Angle Neutron Scattering (SANS), Grazing-Incidence Small-Angle Neutron Scattering (GISANS), X-Ray Diffraction (XRD), Powder X-Ray Diffraction (PXRD), WideAngle X-Ray Diffraction (WAXD), Grazing-Incidence X-Ray Diffraction (GIXD) and Energy-Dispersive X-Ray Diffraction (EDXRD) Comparative Study on Malignant and Benign Human Cancer Cells and Tissues under Synchrotron Radiation", Glob Imaging Insights, Volume 3 (5): 1-10, 2018

288. Heidari, "Nuclear Resonant Inelastic X-Ray Scattering Spectroscopy (NRIXSS) and Nuclear Resonance Vibrational Spectroscopy (NRVS) Comparative Study on Malignant and Benign Human Cancer Cells and Tissues under Synchrotron Radiation", Glob Imaging Insights, Volume 3 (5): 1-7, 2018

289. Heidari, "Small-Angle X-Ray Scattering (SAXS) and Ultra-Small Angle X-Ray Scattering (USAXS) Comparative Study on Malignant and Benign Human Cancer Cells and Tissues under Synchrotron Radiation", Glob Imaging Insights, Volume 3 (5): $1-7,2018$

290. Heidari, "Curious Chloride $(\mathrm{CmCl} 3)$ and Titanic Chloride (TiCl4)-Enhanced Precatalyst Preparation Stabilization and Initiation (EPPSI) Nano Molecules for Cancer Treatment and Cellular Therapeutics", J Cancer Research and Therapeutic Interventions, Volume 1, Issue 1, Pages 01-10, 2018

291. R Gobato, M R R Gobato, Heidari, Mitra, "Spectroscopy and Dipole Moment of the Molecule C13H20BeLi2SeSi via Quantum Chemistry Using Ab Initio, Hartree-Fock Method in the Base Set CC-pVTZ and 6-311G**(3df, 3pd)", Arc Org Inorg Chem Sci 3 (5), Pages 402-409, 2018

292. Heidari, "C60 and C70-Encapsulating Carbon Nanotubes Incorporation into the Nano Polymeric Matrix (NPM) by Immersion of the Nano Polymeric Modified Electrode (NPME) as Molecular Enzymes and Drug Targets for Human Cancer Cells, Tissues and Tumors Treatment under Synchrotron and Synchrocyclotron Radiations", Integr Mol Med, Volume 5 (3): 1-8, 2018 
Heidari A (2020) Types of drug delivery system slide share of protactinium nanoparticles in human gum cancer cells, tissues and tumors treatment under synchrotron radiation

293. Heidari, "Two-Dimensional (2D) $1 \mathrm{H}$ or Proton NMR, 13C NMR, $15 \mathrm{~N}$ NMR and 31P NMR Spectroscopy Comparative Study on Malignant and Benign Human Cance Cells and Tissues under Synchrotron Radiation with the Passage of Time", Glob Imaging Insights, Volume 3 (6): 1-8, 2018

294. Heidari, "FT-Raman Spectroscopy, Coherent Anti-Stokes Raman Spectroscopy (CARS) and Raman Optical Activity Spectroscopy (ROAS) Comparative Study on Malignant and Benign Human Cancer Cells and Tissues with the Passage of Time under Synchrotron Radiation", Glob Imaging Insights, Volume 3 (6): 1-8, 2018

295. Heidari, “A Modern and Comprehensive Investigation of Inelastic Electron Tunneling Spectroscopy (IETS) and Scanning Tunneling Spectroscopy on Malignant and Benign Human Cancer Cells, Tissues and Tumors through Optimizing Synchrotron Microbeam Radiotherapy for Human Cancer Treatments and Diagnostics: An Experimental Biospectroscopic Comparative Study", Glob Imaging Insights, Volume 3 (6): $1-8,2018$

296. Heidari, “A Hypertension Approach to Thermal Infrared Spectroscopy and Photothermal Infrared Spectroscopy Comparative Study on Malignant and Benign Human Cancer Cells and Tissues under Synchrotron Radiation with the Passage of Time", Glob Imaging Insights, Volume 3 (6): 1-8, 2018

297. Heidari, "Incredible Natural-Abundance Double-Quantum Transfer Experiment (INADEQUATE), Nuclear Overhauser Effect Spectroscopy (NOESY) and Rotating Frame Nuclear Overhauser Effect Spectroscopy (ROESY) Comparative Study on Malignant and Benign Human Cancer Cells and Tissues under Synchrotron Radiation”, Glob Imaging Insights, Volume 3 (6): 1-8, 2018

298. Heidari, "2-Amino-9-((1S, 3R, 4R)-4-Hydroxy-3-(Hydroxymethyl)-2Methylenecyclopentyl)-1H-Purin-6(9H)-One, 2-Amino-9-( (1R, 3R, 4R)-4-Hydroxy-3-(Hydroxymethyl)-2-Methylenecyclopentyl)-1H-Purin6(9H)-One, 2-Amino-9-((1R, 3R, 4S)-4-Hydroxy-3-(Hydroxymethyl)-2Methylenecyclopentyl)-1H-Purin-6(9H)-One and 2-Amino-9-((1S, 3R, 4S)-4Hydroxy-3-(Hydroxymethyl)-2-Methylenecyclopentyl)-1H-Purin-6(9H)-OneEnhanced Precatalyst Preparation Stabilization and Initiation Nano Molecules", Glob Imaging Insights, Volume 3 (6): 1-9, 2018

299. R Gobato, M R R Gobato, Heidari, Mitra, "Spectroscopy and Dipole Moment of the Molecule C13H20BeLi2SeSi via Quantum Chemistry Using Ab Initio, Hartree-Fock Method in the Base Set CC-pVTZ and 6-311G**(3df, 3pd)", American Journal of Quantum Chemistry and Molecular Spectroscopy, Vol 2, No 1, pp 9-17, 2018

300. Heidari, "Production of Electrochemiluminescence (ECL) Biosensor Using Os-Pd/ HfC Nanocomposites for Detecting and Tracking of Human Gastroenterological Cancer Cells, Tissues and Tumors", Int J Med Nano Res 5: 1, 022-034, 2018

301. Heidari, "Enhancing the Raman Scattering for Diagnosis and Treatment of Human Cancer Cells, Tissues and Tumors Using Cadmium Oxide (CdO) Nanoparticles", J Toxicol Risk Assess 4: 1, 012-025, 2018

302. Heidari, "Human Malignant and Benign Human Cancer Cells and Tissues Biospectroscopic Analysis under Synchrotron Radiation Using Anti-Cancer Nano Drugs Delivery", Integr Mol Med, Volume 5 (5): 1-13, 2018

303. Heidari, "Analogous Nano Compounds of the Form $\mathrm{M}(\mathrm{C} 8 \mathrm{H} 8) 2$ Exist for $\mathrm{M}=(\mathrm{Nd}$, $\mathrm{Tb}, \mathrm{Pu}, \mathrm{Pa}, \mathrm{Np}, \mathrm{Th}$, and $\mathrm{Yb}$ )-Enhanced Precatalyst Preparation Stabilization and Initiation (EPPSI) Nano Molecules", Integr Mol Med, Volume 5 (5): 1-8, 2018

304. Heidari, "Hadron Spectroscopy, Baryon Spectroscopy and Meson Spectroscopy Comparative Study on Malignant and Benign Human Cancer Cells and Tissues under Synchrotron Radiation", Integr Mol Med, Volume 5 (5): 1-8, 2018

305. R Gobato, M R R Gobato, Heidari, "Raman Spectroscopy Study of the Nano Molecule $\mathrm{C} 13 \mathrm{H} 20 \mathrm{BeLi} 2 \mathrm{SeSi}$ Using ab initio and Hartree-Fock Methods in the Basis Set CC-pVTZ and 6-311G** (3df, 3pd)", International Journal of Advanced Engineering and Science, Volume 7, Number 1, Pages 14-35, 2019

306. Heidari, R Gobato, "Evaluating the Effect of Anti-Cancer Nano Drugs Dosage and Reduced Leukemia and Polycythemia Vera Levels on Trend of the Human Blood and Bone Marrow Cancers under Synchrotron Radiation", Trends in Res, Volume 2 (1): 1-8, 2019

307. Heidari, R Gobato, "Assessing the Variety of Synchrotron, Synchrocyclotron and LASER Radiations and Their Roles and Applications in Human Cancer Cells, Tissue and Tumors Diagnosis and Treatment", Trends in Res, Volume 2 (1): 1-8, 2019

308. Heidari, R Gobato, "Pros and Cons Controversy on Malignant Human Cancer Cells, Tissues and Tumors Transformation Process to Benign Human Cancer Cells, Tissues and Tumors", Trends in Res, Volume 2 (1): 1-8, 2019

309. Heidari, R Gobato, "Three-Dimensional (3D) Simulations of Human Cancer Cells, Tissues and Tumors for Using in Human Cancer Cells, Tissues and Tumors Diagnosis and Treatment as a Powerful Tool in Human Cancer Cells, Tissues and Tumors Research and Anti-Cancer Nano Drugs Sensitivity and Delivery Area Discovery and Evaluation", Trends in Res, Volume 2 (1): 1-8, 2019
310. Heidari, R Gobato, "Investigation of Energy Production by Synchrotron, Synchrocyclotron and LASER Radiations in Human Cancer Cells, Tissues and Tumors and Evaluation of Their Effective on Human Cancer Cells, Tissues and Tumors Treatment Trend", Trends in Res, Volume 2 (1): 1-8, 2019

311. Heidari, R Gobato, "High-Resolution Mapping of DNA/RNA Hypermethylation and Hypomethylation Process in Human Cancer Cells, Tissues and Tumors under Synchrotron Radiation", Trends in Res, Volume 2 (2): 1-9, 2019

312. Heidari, "A Novel and Comprehensive Study on Manufacturing and Fabrication Nanoparticles Methods and Techniques for Processing Cadmium Oxide (CdO) Nanoparticles Colloidal Solution”, Glob Imaging Insights, Volume 4 (1): 1-8, 2019

313. Heidari, "A Combined Experimental and Computational Study on the Catalytic Effect of Aluminum Nitride Nanocrystal (AIN) on the Polymerization of Benzene, Naphthalene, Anthracene, Phenanthrene, Chrysene and Tetracene", Glob Imaging Insights, Volume 4 (1): 1-8, 2019

314. Heidari, "Novel Experimental and Three-Dimensional (3D) Multiphysics Computational Framework of Michaelis-Menten Kinetics for Catalyst Processes Innovation, Characterization and Carrier Applications", Glob Imaging Insights, Volume 4 (1): 1-8, 2019

315. Heidari, "The Hydrolysis Constants of Copper (I) $(\mathrm{Cu}+)$ and Copper (II) $(\mathrm{Cu} 2+)$ in Aqueous Solution as a Function of $\mathrm{pH}$ Using a Combination of $\mathrm{pH}$ Measurement and Biospectroscopic Methods and Techniques", Glob Imaging Insights, Volume 4 (1): $1-8,2019$

316. Heidari, "Vibrational Biospectroscopic Study of Ginormous Virus-Sized Macromolecule and Polypeptide Macromolecule as Mega Macromolecules Using Attenuated Total Reflectance-Fourier Transform Infrared (ATR-FTIR) Spectroscopy and Mathematica 113", Glob Imaging Insights, Volume 4 (1): 1-8, 2019

317. Heidari, "Three-Dimensional (3D) Imaging Spectroscopy of Carcinoma, Sarcoma, Leukemia, Lymphoma, Multiple Myeloma, Melanoma, Brain and Spinal Cord Tumors, Germ Cell Tumors, Neuroendocrine Tumors and Carcinoid Tumors under Synchrotron Radiation", Glob Imaging Insights, Volume 4 (1): 1-9, 2019

318. R Gobato, M R R Gobato, Heidari, "Storm Vortex in the Center of Paraná State on June 6, 2017: A Case Study", Sumerianz Journal of Scientific Research, Vol 2, No 2, Pages 24-31, 2019

319. R Gobato, M R R Gobato, Heidari, “Attenuated Total Reflection-Fourier Transform Infrared (ATR-FTIR) Spectroscopy Study of the Nano Molecule C13H20BeLi2SeSi Using ab initio and Hartree-Fock Methods in the Basis Set RHF/CC-pVTZ and RHF/6-311G** (3df, 3pd): An Experimental Challenge to Chemists", Chemistry Reports, Vol 2, No 1, Pages 1-26, 2019

320. Heidari, "Three-Dimensional (3D) Imaging Spectroscopy of Carcinoma, Sarcoma, Leukemia, Lymphoma, Multiple Myeloma, Melanoma, Brain and Spinal Cord Tumors, Germ Cell Tumors, Neuroendocrine Tumors and Carcinoid Tumors under Synchrocyclotron Radiation”, Res Adv Biomed Sci Technol 1 (1): 01-17, 2019

321. R Gobato, M R R Gobato, Heidari, Mitra, "New Nano-Molecule KurumiC13H20BeLi2SeSi/C13H19BeLi2SeSi, and Raman Spectroscopy Using ab initio, Hartree-Fock Method in the Base Set CC-pVTZ and 6-311G** (3df, 3pd)", J Anal Pharm Res 8 (1): 1-6, 2019

322. Heidari, J Esposito, Caissutti, "The Importance of Attenuated Total Reflectance Fourier Transform Infrared (ATR-FTIR) and Raman Biospectroscopy of SingleWalled Carbon Nanotubes (SWCNT) and Multi-Walled Carbon Nanotubes (MWCNT) in Interpreting Infrared and Raman Spectra of Human Cancer Cells, Tissues and Tumors", Oncogen 2 (2): 1-21, 2019

323. Heidari, "Mechanism of Action and Their Side Effects at a Glance Prevention, Treatment and Management of Immune System and Human Cancer Nano Chemotherapy", Nanosci Technol 6 (1): 1-4, 2019

324. Heidari, J Esposito, Caissutti, "The Quantum Entanglement Dynamics Induced by Non-Linear Interaction between a Moving Nano Molecule and a Two-Mode Field with Two-Photon Transitions Using Reduced Von Neumann Entropy and JaynesCummings Model for Human Cancer Cells, Tissues and Tumors Diagnosis", Int J Crit Care Emerg Med 5 (2): 071-084, 2019

325. Heidari, J Esposito, Caissutti, "Palytoxin Time-Resolved Absorption and Resonance FT-IR and Raman Biospectroscopy and Density Functional Theory (DFT) Investigation of Vibronic-Mode Coupling Structure in Vibrational Spectra Analysis", J Pharm Drug Res, 3 (1): 150-170, 2019

326. Heidari, J Esposito, Caissutti, "Aplysiatoxin Time-Resolved Absorption and Resonance FT-IR and Raman Biospectroscopy and Density Functional Theory (DFT) Investigation of Vibronic-Mode Coupling Structure in Vibrational Spectra Analysis", J Chem Sci Eng, 2 (2): 70-89, 2019 
Heidari A (2020) Types of drug delivery system slide share of protactinium nanoparticles in human gum cancer cells, tissues and tumors treatment under synchrotron radiation

327. R Gobato, M R R Gobato, Heidari, Mitra, "Spectroscopy and Dipole Moment of the Molecule C13H20BeLi2SeSi via Quantum Chemistry Using Ab initio, Hartree-Fock Method in the Base Set CC-pVTZ and 6-311G** (3df, 3pd)", American Journal of Quantum Chemistry and Molecular Spectroscopy, 2 (1): 9-17, 2018

328. Heidari, J Esposito, Caissutti, "Cyanotoxin Time-Resolved Absorption and Resonance FT-IR and Raman Biospectroscopy and Density Functional Theory (DFT) Investigation of Vibronic-Mode Coupling Structure in Vibrational Spectra Analysis", Br J Med Health Res 6 (04): 21-60, 2019

329. Heidari, "Potential and Theranostics Applications of Novel Anti-Cancer Nano Drugs Delivery Systems in Preparing for Clinical Trials of Synchrotron Microbeam Radiation Therapy (SMRT) and Synchrotron Stereotactic Radiotherapy (SSRT) for Treatment of Human Cancer Cells, Tissues and Tumors Using Image Guided Synchrotron Radiotherapy (IGSR)", Ann Nanosci Nanotechnol 3 (1): 1006-1019, 2019

330. Heidari, J Esposito, Caissutti, "Study of Anti-Cancer Properties of Thin Layers of Cadmium Oxide (CdO) Nanostructure", Int J Analyt Bioanalyt Methods 1 (1): 003-022, 2019

331. Heidari, J Esposito, Caissutti, "Alpha-Conotoxin, Omega-Conotoxin and $\mathrm{Mu}-$ Conotoxin Time-Resolved Absorption and Resonance FT-IR and Raman Biospectroscopy and Density Functional Theory (DFT) Investigation of VibronicMode Coupling Structure in Vibrational Spectra Analysis", International Journal of Advanced Chemistry, 7 (1) 52-66, 2019

332. Heidari, "Clinical and Medical Pros and Cons of Human Cancer Cells'Enzymotherapy, Immunotherapy, Chemotherapy, Radiotherapy, Hormone Therapy and Targeted Therapy Process under Synchrotron Radiation: A Case Study on Mechanism of Action and Their Side Effects", Parana Journal of Science and Education (PJSE)-v 5, n 3, (1-23) May 2, 2019

333. Heidari, "The Importance of the Power in CMOS Inverter Circuit of Synchrotron and Synchrocyclotron Radiations Using $50(\mathrm{~nm})$ and $100(\mathrm{~nm})$ Technologies and Reducing the Voltage of Power Supply", Radiother Oncol Int 1 (1): 1002-1015, 2019

334. Heidari, J Esposito, Caissutti, "The Importance of Quantum Hydrodynamics (QHD) Approach to Single-Walled Carbon Nanotubes (SWCNT) and Multi-Walled Carbon Nanotubes (MWCNT) in Genetic Science", SCIOL Genet Sci 2 (1): 113-129, 2019

335. Heidari, J Esposito, Caissutti, "Anatoxin-a and Anatoxin-a(s) Time-Resolved Absorption and Resonance FT-IR and Raman Biospectroscopy and Density Functional Theory (DFT) Investigation of Vibronic-Mode Coupling Structure in Vibrational Spectra Analysis", Saudi J Biomed Res, 4 (4): 174-194, 2019

336. R Gobato, M R R Gobato, Heidari, "Evidence of Tornado Storm Hit the Counties of Rio Branco do Ivaí and Rosario de Ivaí, Southern Brazil”, Sci Lett, 7 (1): 32-40, 2019

337. M Jeyaraj, V Mahalingam, Indhuleka, P Sennu, M S Ho, Heidari, "Chemical Analysis of Surface Water Quality of River Noyyal Connected Tank in Tirupur District, Tamil Nadu, India”, Water and Energy International, Volume 62r, Issue 1, pp 63-68, 2019

338. Heidari, J Esposito, Caissutti, "6-Methoxy-8-[[6-Methoxy-8-[[6-Methoxy-2Methyl-1-(2-Methylpropyl)-3,4- Dihydro-1H-Isoquinolin-7-yl]Oxy]-2Methyl-1-(2-Methylpropyl)-3,4-Dihydro-1H-Isoquinolin-7-yl]Oxy]-2Methyl-1-(2-Methylpropyl)-3,4-Dihydro-1H-Isoquinolin-7-ol Time-Resolved Absorption and Resonance FT-IR and Raman Biospectroscopy and Density Functional Theory (DFT) Investigation of Vibronic-Mode Coupling Structure in Vibrational Spectra Analysis", J Adv Phys Chem, Volume 1, Issue 1, pp 1-6, 2019

339. Heidari, J Esposito, Caissutti, "Shiga Toxin and Shiga-Like Toxin (SLT) TimeResolved Absorption and Resonance FT-IR and Raman Biospectroscopy and Density Functional Theory (DFT) Investigation of Vibronic-Mode Coupling Structure in Vibrational Spectra Analysis”, Annal Biostat \& Biomed Appli 2 (3): 1-4, 2019

340. Heidari, J Esposito, Caissutti, "Alpha-Bungarotoxin, Beta-Bungarotoxin and Kappa-Bungarotoxin Time-Resolved Absorption and Resonance FT-IR and Raman Biospectroscopy and Density Functional Theory (DFT) Investigation of Vibronic-Mode Coupling Structure in Vibrational Spectra Analysis", Archives of Pharmacology and Pharmaceutical Sciences, ReDelve, Volume 2019, Issue 01, pp $1-24,2019$

341. Heidari, J Esposito, Caissutti, "Okadaic Acid Time-Resolved Absorption and Resonance FT-IR and Raman Biospectroscopy and Density Functional Theory (DFT) Investigation of Vibronic-Mode Coupling Structure in Vibrational Spectra Analysis”, Int J Analyt Bioanalyt Methods 1 (1): 1-19, 2019

342. Heidari, "Investigation of the Processes of Absorption, Distribution, Metabolism and Elimination (ADME) as Vital and Important Factors for Modulating Drug Action and Toxicity", Open Access J Oncol, 2 (1): 180010-180012, 2019
343. Heidari, J Esposito, Caissutti, "Pertussis Toxin Time-Resolved Absorption and Resonance FT-IR and Raman Biospectroscopy and Density Functional Theory (DFT) Investigation of Vibronic-Mode Coupling Structure in Vibrational Spectra Analysis", Chemistry Reports, Vol 1 Iss 2, Pages 1-5, 2019

344. R Gobato, M R R Gobato, Heidari, "Rhodochrosite as Crystal Oscillator", Am J Biomed Sci \& Res 3 (2), 187, 2019

345. Heidari, J Esposito, Caissutti, "Tetrodotoxin (TTX) Time-Resolved Absorption and Resonance FT-IR and Raman Biospectroscopy and Density Functional Theory (DFT) Investigation of Vibronic-Mode Coupling Structure in Vibrational Spectra Analysis", Journal of New Developments in Chemistry, Volume No: 2, Issue No: 3, Page Numbers 26-48, 2019

346. Heidari, J Esposito, Caissutti, "The Importance of Analysis of Vibronic-Mode Coupling Structure in Vibrational Spectra of Supramolecular Aggregates of $(C A * M)$ Cyanuric Acid (CA) and Melamine (M) beyond the Franck-Condon Approximation", Journal of Clinical and Medical Images, 2 (2): 1-20, 2019

347. Heidari, J Esposito, Caissutti, "Microcystin-LR Time-Resolved Absorption and Resonance FT-IR and Raman Biospectroscopy and Density Functional Theory (DFT) Investigation of Vibronic-Mode Coupling Structure in Vibrational Spectra Analysis", Malaysian Journal of Chemistry, Vol 21 (1), 70-95, 2019

348. Heidari, J Esposito, Caissutti, "Botulinum Toxin Time-Resolved Absorption and Resonance FT-IR and Raman Biospectroscopy and Density Functional Theory (DFT) Investigation of Vibronic-Mode Coupling Structure in Vibrational Spectra Analysis", Journal of Mechanical Design and Vibration, vol 7, no 1: 1-15, 2019

349. Heidari, J Esposito, Caissutti, "Domoic Acid (DA) Time-Resolved Absorption and Resonance FT-IR and Raman Biospectroscopy and Density Functional Theory (DFT) Investigation of Vibronic-Mode Coupling Structure in Vibrational Spectra Analysis", Cientific Clinical Oncology Journal 1 2: 03-07, 2019

350. Heidari, J Esposito, Caissutti, "Surugatoxin (SGTX) Time-Resolved Absorption and Resonance FT-IR and Raman Biospectroscopy and Density Functional Theory (DFT) Investigation of Vibronic-Mode Coupling Structure in Vibrational Spectra Analysis", Cientific Clinical Oncology Journal 1 2: 14-18, 2019

351. Heidari, J Esposito, Caissutti, "Decarbamoylsaxitoxin Time-Resolved Absorption and Resonance FT-IR and Raman Biospectroscopy and Density Functional Theory (DFT) Investigation of Vibronic-Mode Coupling Structure in Vibrational Spectra Analysis", Cientific Clinical Oncology Journal 1 2: 19-23, 2019

352. Heidari, J Esposito, Caissutti, "Gonyautoxin (GTX) Time-Resolved Absorption and Resonance FT-IR and Raman Biospectroscopy and Density Functional Theory (DFT) Investigation of Vibronic-Mode Coupling Structure in Vibrational Spectra Analysis", Cientific Clinical Oncology Journal 1 2: 24-28, 2019

353. Heidari, J Esposito, Caissutti, "Hislrionicotoxin Time-Resolved Absorption and Resonance FT-IR and Raman Biospectroscopy and Density Functional Theory (DFT) Investigation of Vibronic-Mode Coupling Structure in Vibrational Spectra Analysis", Cientific Drug Delivery Research 1 1: 01-06, 2019

354. Heidari, J Esposito, Caissutti, "Dihydrokainic Acid Time-Resolved Absorption and Resonance FT-IR and Raman Biospectroscopy and Density Functional Theory (DFT) Investigation of Vibronic-Mode Coupling Structure in Vibrational Spectra Analysis", Cientific Drug Delivery Research 1 1:07-12, 2019

355. Heidari, J Esposito, Caissutti, “Aflatoxin B1 (AFB1), B2 (AFB2), G1 (AFG1), G2 (AFG2), M1 (AFM1), M2 (AFM2), Q1 (AFQ1) and P1 (AFP1) Time-Resolved Absorption and Resonance FT-IR and Raman Biospectroscopy and Density Functional Theory (DFT) Investigation of Vibronic-Mode Coupling Structure in Vibrational Spectra Analysis", Cientific Drug Delivery Research 1 1: 25-32, 2019

356. Heidari, J Esposito, Caissutti, "Mycotoxin Time-Resolved Absorption and Resonance FT-IR and Raman Biospectroscopy and Density Functional Theory (DFT) Investigation of Vibronic-Mode Coupling Structure in Vibrational Spectra Analysis", Cientific Drug Delivery Research 1 1: 13-18, 2019

357. Heidari, J Esposito, Caissutti, "Bufotoxin Time-Resolved Absorption and Resonance FT-IR and Raman Biospectroscopy and Density Functional Theory (DFT) Investigation of Vibronic-Mode Coupling Structure in Vibrational Spectra Analysis", Cientific Drug Delivery Research 1 1: 19-24, 2019

358. Heidari, J Esposito, Caissutti, "Kainic Acid (Kainite) Time-Resolved Absorption and Resonance FT-IR and Raman Biospectroscopy and Density Functional Theory (DFT) Investigation of Vibronic-Mode Coupling Structure in Vibrational Spectra Analysis", Cientific Journal of Neurology 1 2: 02-07, 2019

359. Heidari, J Esposito, Caissutti, "Nereistoxin Time-Resolved Absorption and Resonance FT-IR and Raman Biospectroscopy and Density Functional Theory (DFT) Investigation of Vibronic-Mode Coupling Structure in Vibrational Spectra Analysis", Cientific Journal of Neurology 1 2: 19-24, 2019 
Heidari A (2020) Types of drug delivery system slide share of protactinium nanoparticles in human gum cancer cells, tissues and tumors treatment under synchrotron radiation

360. Heidari, J Esposito, Caissutti, "Spider Toxin and Raventoxin Time-Resolved Absorption and Resonance FT-IR and Raman Biospectroscopy and Density Functional Theory (DFT) Investigation of Vibronic-Mode Coupling Structure in Vibrational Spectra Analysis", Parana Journal of Science and Education Vol 5, No 4, pp 1-28, 2019

361. Heidari, J Esposito, Caissutti, "Ochratoxin A, Ochratoxin B, Ochratoxin C, Ochratoxin $\alpha$ and Ochratoxin TA Time-Resolved Absorption and Resonance FT-IR and Raman Biospectroscopy and Density Functional Theory (DFT) Investigation of Vibronic-Mode Coupling Structure in Vibrational Spectra Analysis”, Cientific Drug Delivery Research 1 2: 03-10, 2019

362. Heidari, J Esposito, Caissutti, "Brevetoxin A and B Time-Resolved Absorption and Resonance FT-IR and Raman Biospectroscopy and Density Functional Theory (DFT) Investigation of Vibronic-Mode Coupling Structure in Vibrational Spectra Analysis", Cientific Drug Delivery Research 12 : 11-16, 2019

363. Heidari, J Esposito, Caissutti, "Lyngbyatoxin-a Time-Resolved Absorption and Resonance FT-IR and Raman Biospectroscopy and Density Functional Theory (DFT) Investigation of Vibronic-Mode Coupling Structure in Vibrational Spectra Analysis", Cientific Drug Delivery Research 1 2: 23-28, 2019

364. Heidari, J Esposito, Caissutti, "Balraechotoxin (BTX) Time-Resolved Absorption and Resonance FT-IR and Raman Biospectroscopy and Density Functional Theory (DFT) Investigation of Vibronic-Mode Coupling Structure in Vibrational Spectra Analysis", Cientific Journal of Neurology 1 3: 01-05, 2019

365. Heidari, J Esposito, Caissutti, "Hanatoxin Time-Resolved Absorption and Resonance FT-IR and Raman Biospectroscopy and Density Functional Theory (DFT) Investigation of Vibronic-Mode Coupling Structure in Vibrational Spectra Analysis", Int J Pharm Sci Rev Res, 57 (1), Pages: 21-32, 2019

366. Heidari, J Esposito, Caissutti, "Neurotoxin and Alpha-Neurotoxin Time-Resolved Absorption and Resonance FT-IR and Raman Biospectroscopy and Density Functional Theory (DFT) Investigation of Vibronic-Mode Coupling Structure in Vibrational Spectra Analysis", J Biomed Sci \& Res 3 (6), 550-563, 2019

367. Heidari, J Esposito, Caissutti, “Antillatoxin (ATX) Time-Resolved Absorption and Resonance FT-IR and Raman Biospectroscopy and Density Functional Theory (DFT) Investigation of Vibronic-Mode Coupling Structure", American Journal of Optics and Photonics Vol 7, No 1, pp 18-27, 2019

368. R Gobato, M R R Gobato, Heidari, "Calculation by UFF Method of Frequencies and Vibrational Temperatures of the Unit Cell of the Rhodochrosite Crystal", International Journal of Advanced Chemistry, 7 (2) 77-81, 2019

369. Heidari, J Esposito, Caissutti, "Analysis of Vibronic-Mode Coupling Structure in Vibrational Spectra of Fuzeon as a 36 Amino Acid Peptide for HIV Therapy beyond the Multi-Dimensional Franck-Condon Integrals Approximation", International Journal of Advanced Chemistry, 7 (2) 82-96, 2019

370. Heidari, J Esposito, Caissutti, "Debromoaplysiatoxin Time-Resolved Absorption and Resonance FT-IR and Raman Biospectroscopy and Density Functional Theory (DFT) Investigation of Vibronic-Mode Coupling Structure in Vibrational Spectra Analysis", Applied Chemistry, 2 (1) 17-54, 2019

371. Heidari, J Esposito, Caissutti, "Enterotoxin Time-Resolved Absorption and Resonance FT-IR and Raman Biospectroscopy and Density Functional Theory (DFT) Investigation of Vibronic-Mode Coupling Structure in Vibrational Spectra Analysis", JRL J Sci Technol vol1-iss2: jst1001, 1-16, 2019

372. R Gobato, M R R Gobato, Heidari, Mitra, "Rhodochrosite Optical Indicatrix", Peer Res Nest 1 (3) 1-2, 2019

373. Heidari, J Esposito, Caissutti, "Anthrax Toxin Time-Resolved Absorption and Resonance FT-IR and Raman Biospectroscopy and Density Functional Theory (DFT) Investigation of Vibronic-Mode Coupling Structure in Vibrational Spectra Analysis", Research \& Reviews: Journal of Computational Biology 8 (2): 23-51, 2019

374. Heidari, J Esposito, Caissutti, "Kalkitoxin Time-Resolved Absorption and Resonance FT-IR and Raman Biospectroscopy and Density Functional Theory (DFT) Investigation of Vibronic-Mode Coupling Structure in Vibrational Spectra Analysis", Can J Biomed Res \& Tech 2 (1): 1-21, 2019

375. Heidari, J Esposito, Caissutti, "Neosaxitoxin Time-Resolved Absorption and Resonance FT-IR and Raman Biospectroscopy and Density Functional Theory (DFT) Investigation of Vibronic-Mode Coupling Structure in Vibrational Spectra Analysis", Clin Case Studie Rep, Volume 2 (3): 1-14, 2019

376. Heidari, J Esposito, Caissutti, "6-Methoxy-8-[[6-Methoxy-8-[[6- Methoxy-2Methyl-1-(2-Methylpropyl)-3,4-Dihydro-1H-Isoquinolin-7-yl]Oxy]-2Methyl-1-(2-Methylpropyl)-3,4-Dihydro-1H-Isoquinolin-7-yl]Oxy]-2Methyl-1-(2- Methylpropyl)-3,4-Dihydro-1H-Isoquinolin-7-ol Time-Resolved
Absorption and Resonance FT-IR and Raman Biospectroscopy and Density Functional Theory (DFT) Investigation of Vibronic-Mode Coupling Structure in Vibrational Spectra Analysis", Clin Case Studie Rep, Volume 2 (3): 1-14, 2019

377. Heidari, "Comparison of Synchrotron Radiation and Synchrocyclotron Radiation Performance in Monitoring of Human Cancer Cells, Tissues and Tumors", Clin Case Studie Rep, Volume 2 (3): 1-12, 2019

378. Heidari, J Esposito, Caissutti, "Kalkitoxin Time-Resolved Absorption and Resonance FT-IR and Raman Biospectroscopy and Density Functional Theory (DFT) Investigation of Vibronic-Mode Coupling Structure in Vibrational Spectra Analysis", Clin Case Studie Rep, Volume 2 (3): 1-14, 2019

379. Heidari, J Esposito, Caissutti, "Diphtheria Toxin Time-Resolved Absorption and Resonance FT-IR and Raman Biospectroscopy and Density Functional Theory (DFT) Investigation of Vibronic-Mode Coupling Structure in Vibrational Spectra Analysis: A Spectroscopic Study on an Anti-Cancer Drug", Clin Case Studie Rep, Volume 2 (3): 1-14, 2019

380. Heidari, J Esposito, Caissutti, "Symbiodinolide Time-Resolved Absorption and Resonance FT-IR and Raman Biospectroscopy and Density Functional Theory (DFT) Investigation of Vibronic-Mode Coupling Structure in Vibrational Spectra Analysis", Clin Case Studie Rep, Volume 2 (3): 1-14, 2019

381. Heidari, J Esposito, Caissutti, "Saxitoxin Time-Resolved Absorption and Resonance FT-IR and Raman Biospectroscopy and Density Functional Theory Investigation of Vibronic-Mode Coupling Structure in Vibrational Spectra Analysis", Am J Exp Clin Res 6 (4): 364-377, 2019

382. Heidari, J Esposito, Caissutti, "Gonyautoxin (GTX) Time-Resolved Absorption and Resonance FT-IR and Raman Biospectroscopy and Density Functional Theory (DFT) Investigation of Vibronic-Mode Coupling Structure in Vibrational Spectra Analysis", Cientific Clinical Oncology Journal 1 2: 24-28, 2019

383. Heidari, J Esposito, Caissutti, "Hislrionicotoxin Time-Resolved Absorption and Resonance FT-IR and Raman Biospectroscopy and Density Functional Theory (DFT) Investigation of Vibronic-Mode Coupling Structure in Vibrational Spectra Analysis", Cientific Drug Delivery Research 1 1: 01-06, 2019

384. Heidari, J Esposito, Caissutti, "Dihydrokainic Acid Time-Resolved Absorption and Resonance FT-IR and Raman Biospectroscopy and Density Functional Theory (DFT) Investigation of Vibronic-Mode Coupling Structure in Vibrational Spectra Analysis", Cientific Drug Delivery Research 1 1: 07-12, 2019

385. Heidari, J Esposito, Caissutti, “Aflatoxin B1 (AFB1), B2 (AFB2), G1 (AFG1), G2 (AFG2), M1 (AFM1), M2 (AFM2), Q1 (AFQ1) and P1 (AFP1) Time- Resolved Absorption and Resonance FT-IR and Raman Biospectroscopy and Density Functional Theory (DFT) Investigation of Vibronic-Mode Coupling Structure in Vibrational Spectra Analysis”, Cientific Drug Delivery Research 1 1: 25-32, 2019

386. Heidari, J Esposito, Caissutti, "Mycotoxin Time-Resolved Absorption and Resonance FT-IR and Raman Biospectroscopy and Density Functional Theory (DFT) Investigation of Vibronic-Mode Coupling Structure in Vibrational Spectra Analysis”, Cientific Drug Delivery Research 1 1: 13-18, 2019

387. Heidari, J Esposito, Caissutti, "Bufotoxin Time-Resolved Absorption and Resonance FT-IR and Raman Biospectroscopy and Density Functional Theory (DFT) Investigation of Vibronic-Mode Coupling Structure in Vibrational Spectra Analysis", Cientific Drug Delivery Research 1 1: 19-24, 2019

388. Heidari, J Esposito, Caissutti, "Kainic Acid (Kainite) Time-Resolved Absorption and Resonance FT-IR and Raman Biospectroscopy and Density Functional Theory (DFT) Investigation of Vibronic-Mode Coupling Structure in Vibrational Spectra Analysis", Cientific Journal of Neurology 1 2: 02-07, 2019

389. Heidari, J Esposito, Caissutti, "Nereistoxin Time-Resolved Absorption and Resonance FT-IR and Raman Biospectroscopy and Density Functional Theory (DFT) Investigation of Vibronic-Mode Coupling Structure in Vibrational Spectra Analysis", Cientific Journal of Neurology 1 2: 19-24, 2019

390. Heidari, J Esposito, Caissutti, "Spider Toxin and Raventoxin Time-Resolved Absorption and Resonance FT-IR and Raman Biospectroscopy and Density Functional Theory (DFT) Investigation of Vibronic-Mode Coupling Structure in Vibrational Spectra Analysis", Parana Journal of Science and Education Vol 5, No 4, pp 1-28, 2019

391. Heidari, J Esposito, Caissutti, "Ochratoxin A, Ochratoxin B, Ochratoxin C, Ochratoxin $\alpha$ and Ochratoxin TA Time-Resolved Absorption and Resonance FT-IR and Raman Biospectroscopy and Density Functional Theory (DFT) Investigation of Vibronic-Mode Coupling Structure in Vibrational Spectra Analysis", Cientific Drug Delivery Research 1 2: 03-10, 2019 
Heidari A (2020) Types of drug delivery system slide share of protactinium nanoparticles in human gum cancer cells, tissues and tumors treatment under synchrotron radiation

392. Heidari, J Esposito, Caissutti, "Brevetoxin A and B Time-Resolved Absorption and Resonance FT-IR and Raman Biospectroscopy and Density Functional Theory (DFT) Investigation of Vibronic-Mode Coupling Structure in Vibrational Spectra Analysis", Cientific Drug Delivery Research $12: 11-16,2019$

393. Heidari, J Esposito, Caissutti, "Lyngbyatoxin-a Time-Resolved Absorption and Resonance FT-IR and Raman Biospectroscopy and Density Functional Theory (DFT) Investigation of Vibronic-Mode Coupling Structure in Vibrational Spectra Analysis", Cientific Drug Delivery Research 1 2: 23-28, 2019

394. Heidari, J Esposito, Caissutti, "Balraechotoxin (BTX) Time-Resolved Absorption and Resonance FT-IR and Raman Biospectroscopy and Density Functional Theory (DFT) Investigation of Vibronic-Mode Coupling Structure in Vibrational Spectra Analysis", Cientific Journal of Neurology 1 3: 01-05, 2019

395. Heidari, J Esposito, Caissutti, "Hanatoxin Time-Resolved Absorption and Resonance FT-IR and Raman Biospectroscopy and Density Functional Theory (DFT) Investigation of Vibronic-Mode Coupling Structure in Vibrational Spectra Analysis", Int J Pharm Sci Rev Res, 57 (1), Pages: 21-32, 2019

396. Heidari, J Esposito, Caissutti, "Neurotoxin and Alpha-Neurotoxin Time- Resolved Absorption and Resonance FT-IR and Raman Biospectroscopy and Density Functional Theory (DFT) Investigation of Vibronic-Mode Coupling Structure in Vibrational Spectra Analysis", J Biomed Sci \& Res 3 (6), 550-563, 2019

397. Heidari, J Esposito, Caissutti, "Antillatoxin (ATX) Time-Resolved Absorption and Resonance FT-IR and Raman Biospectroscopy and Density Functional Theory (DFT) Investigation of Vibronic-Mode Coupling Structure", American Journal of Optics and Photonics Vol 7, No 1, pp 18-27, 2019

398. R Gobato, M R R Gobato, Heidari, "Calculation by UFF Method of Frequencies and Vibrational Temperatures of the Unit Cell of the Rhodochrosite Crystal", International Journal of Advanced Chemistry, 7 (2) 77-81, 2019

399. Heidari, J Esposito, Caissutti, "Analysis of Vibronic-Mode Coupling Structure in Vibrational Spectra of Fuzeon as a 36 Amino Acid Peptide for HIV Therapy beyond the Multi-Dimensional Franck-Condon Integrals Approximation", International Journal of Advanced Chemistry, 7 (2) 82-96, 2019

400. Heidari, J Esposito, Caissutti, "Debromoaplysiatoxin Time-Resolved Absorption and Resonance FT-IR and Raman Biospectroscopy and Density Functional Theory (DFT) Investigation of Vibronic-Mode Coupling Structure in Vibrational Spectra Analysis", Applied Chemistry, 2 (1) 17-54, 2019

401. Heidari, J Esposito, Caissutti, "Enterotoxin Time-Resolved Absorption and Resonance FT-IR and Raman Biospectroscopy and Density Functional Theory (DFT) Investigation of Vibronic-Mode Coupling Structure in Vibrational Spectra Analysis”, JRL J Sci Technol vol1-iss2: jst1001, 1-16, 2019

402. R Gobato, M R R Gobato, Heidari, Mitra, "Rhodochrosite Optical Indicatrix", Peer Res Nest 1 (3) 1-2, 2019

403. Heidari, J Esposito, Caissutti, "Anthrax Toxin Time-Resolved Absorption and Resonance FT-IR and Raman Biospectroscopy and Density Functional Theory (DFT) Investigation of Vibronic-Mode Coupling Structure in Vibrational Spectra Analysis", Research \& Reviews: Journal of Computational Biology 8 (2): 23-51, 2019

404. Heidari, J Esposito, Caissutti, "Kalkitoxin Time-Resolved Absorption and Resonance FT-IR and Raman Biospectroscopy and Density Functional Theory (DFT) Investigation of Vibronic-Mode Coupling Structure in Vibrational Spectra Analysis", Can J Biomed Res \& Tech 2 (1): 1-21, 2019

405. Heidari, J Esposito, Caissutti, "Neosaxitoxin Time-Resolved Absorption and Resonance FT-IR and Raman Biospectroscopy and Density Functional Theory (DFT) Investigation of Vibronic-Mode Coupling Structure in Vibrational Spectra Analysis", Clin Case Studie Rep, Volume 2 (3): 1-14, 2019

406. Heidari, J Esposito, Caissutti, "6-Methoxy-8-[[6-Methoxy-8-[[6- Methoxy-2Methyl-1-(2-Methylpropyl)-3,4-Dihydro-1H-Isoquinolin-7-yl]Oxy]-2Methyl-1-(2-Methylpropyl)-3,4-Dihydro-1H-Isoquinolin-7-yl]Oxy]-2Methyl-1-(2-Methylpropyl)-3,4-Dihydro-1H-Isoquinolin-7-ol Time-Resolved Absorption and Resonance FT-IR and Raman Biospectroscopy and Density Functional Theory (DFT) Investigation of Vibronic-Mode Coupling Structure in Vibrational Spectra Analysis", Clin Case Studie Rep, Volume 2 (3): 1-14, 2019

407. Heidari, "Comparison of Synchrotron Radiation and Synchrocyclotron Radiation Performance in Monitoring of Human Cancer Cells, Tissues and Tumors", Clin Case Studie Rep, Volume 2 (3): 1-12, 2019

408. Heidari, J Esposito, Caissutti, "Kalkitoxin Time-Resolved Absorption and Resonance FT-IR and Raman Biospectroscopy and Density Functional Theory (DFT) Investigation of Vibronic-Mode Coupling Structure in Vibrational Spectra Analysis", Clin Case Studie Rep, Volume 2 (3): 1-14, 2019
409. Heidari, J Esposito, Caissutti, "Diphtheria Toxin Time-Resolved Absorption and Resonance FT-IR and Raman Biospectroscopy and Density Functional Theory (DFT) Investigation of Vibronic-Mode Coupling Structure in Vibrational Spectra Analysis: A Spectroscopic Study on an Anti-Cancer Drug", Clin Case Studie Rep, Volume 2 (3): 1-14, 2019

410. Heidari, J Esposito, Caissutti, "Symbiodinolide Time-Resolved Absorption and Resonance FT-IR and Raman Biospectroscopy and Density Functional Theory (DFT) Investigation of Vibronic-Mode Coupling Structure in Vibrational Spectra Analysis”, Clin Case Studie Rep, Volume 2 (3): 1-14, 2019

411. Heidari, J Esposito, Caissutti, "Saxitoxin Time-Resolved Absorption and Resonance FT-IR and Raman Biospectroscopy and Density Functional Theory Investigation of Vibronic-Mode Coupling Structure in Vibrational Spectra Analysis", Am J Exp Clin Res 6 (4): 364-377, 2019

412. R Gobato, M R R Gobato, Heidari, Mitra, "Hartree-Fock Methods Analysis Protonated Rhodochrosite Crystal and Potential in the Elimination of Cancer Cells through Synchrotron Radiation", Vol 5, No 3, pp 27-36, 2019

413. R Gobato, I K K Dosh, Heidari, Mitra, M R R Gobato, "Perspectives on the Elimination of Cancer Cells Using Rhodochrosite Crystal Through Synchrotron Radiation, and Absorption the Tumoral and Non-Tumoral Tissues", Arch Biomed Eng \& Biotechnol 3 (2): 1-2, 2019

414. R Gobato, M R R Gobato, Heidari, Mitra, "Unrestricted Hartree-Fock Computational Simulation in a Protonated Rhodochrosite Crystal", Phys Astron Int J 3 (6):220-228, 2019

415. Heidari, K Schmitt, M Henderson, E Besana, "Perspectives on Sub- Nanometer Level of Electronic Structure of the Synchrotron with Mendelevium Nanoparticles for Elimination of Human Cancer Cells, Tissues and Tumors Treatment Using Mathematica 120", Journal of Energy Conservation, Volume 1, Issue 2, Pages 46-73, 2019

416. Heidari, K Schmitt, M Henderson, E Besana, "Simulation of Interaction of Synchrotron Radiation Emission as a Function of the Beam Energy and Bohrium Nanoparticles Using 3D Finite Element Method (FEM) as an Optothermal Human Cancer Cells, Tissues and Tumors Treatment", Current Research in Biochemistry and Molecular Biology, 1 (1), 17-44, 2019

417. Heidari, K Schmitt, M Henderson, E Besana, "Investigation of Interaction between Synchrotron Radiation and Thulium Nanoparticles for Human Cancer Cells, Tissues and Tumors Treatment", European Journal of Scientific Exploration, Volume 2, Issue 3, Pages 1-8, 2019

418. Heidari, K Schmitt, M Henderson, E Besana, "The Effectiveness of the Treatment Human Cancer Cells, Tissues and Tumors Using Darmstadtium Nanoparticles and Synchrotron Radiation", International Journal of Advanced Engineering and Science, Volume 9, Number 1, Pages 9-39, 2020

419. Heidari, K Schmitt, M Henderson, E Besana, "Using 3D Finite Element Method (FEM) as an Optothermal Human Cancer Cells, Tissues and Tumors Treatment in Simulation of Interaction of Synchrotron Radiation Emission as a Function of the Beam Energy and Uranium Nanoparticles", Nano Prog, 1 (2), 1-6, 2019

420. Heidari, K Schmitt, M Henderson, E Besana, "A New Approach to Interaction between Beam Energy and Erbium Nanoparticles”, Saudi J Biomed Res, 4 (11): 372-396, 2019

421. Heidari, K Schmitt, M Henderson, E Besana, "Consideration of Energy Functions and Wave Functions of the Synchrotron Radiation and Samarium Nanoparticles Interaction During Human Cancer Cells, Tissues and Tumors Treatment Process", Sci Int (Lahore), 31 (6), 885-908, 2019

422. Heidari, K Schmitt, M Henderson, E Besana, "An Outlook on Optothermal Human Cancer Cells, Tissues and Tumors Treatment Using Lanthanum Nanoparticles under Synchrotron Radiation", Journal of Materials Physics and Chemistry, Vol 7, No 1, 29-45, 2019

423. Heidari, K Schmitt, M Henderson, E Besana, "Effectiveness of Einsteinium Nanoparticles in Optothermal Human Cancer Cells, Tissues and Tumors Treatment under Synchrotron Radiation”, Journal of Analytical Oncology, 8, 1, 43-62, 2019

424. Heidari, K Schmitt, M Henderson, E Besana, "Study of Relation between Synchrotron Radiation and Dubnium Nanoparticles in Human Cancer Cells, Tissues and Tumors Treatment Process", Int Res J Applied Sci, Volume 1, Number 4, Pages 1-20, 2019 

radiation

425. Heidari, K Schmitt, M Henderson, E Besana, "A Novel Prospect on Interaction of Synchrotron Radiation Emission and Europium Nanoparticles for Human Cancer Cells, Tissues and Tumors Treatment", European Modern Studies Journal, 3 (5), 11-24, 2019

426. Heidari, K Schmitt, M Henderson, E Besana, "Advantages, Effectiveness and Efficiency of Using Neodymium Nanoparticles by 3D Finite Element Method (FEM) as an Optothermal Human Cancer Cells, Tissues and Tumors Treatment under Synchrotron Radiation”, International Journal of Advanced Chemistry, 7 (2) $119-135,2019$

427. Heidari, K Schmitt, M Henderson, E Besana, "Role and Applications of Promethium Nanoparticles in Human Cancer Cells, Tissues and Tumors Treatment", Scientific Modelling and Research, 4 (1): 8-14, 2019

428. Heidari, J Esposito, Caissutti, "Maitotoxin Time-Resolved Absorption and Resonance FT-IR and Raman Biospectroscopy and Density Functional Theory (DFT) Investigation of Vibronic-Mode Coupling Structure in Vibrational Spectra Analysis: A Spectroscopic Study on an Anti-Cancer Drug”, Glob Imaging Insights $4(2), 1-13,2019$

429. Heidari, J Esposito, Caissutti, "Biotoxin Time-Resolved Absorption and Resonance FT-IR and Raman Biospectroscopy and Density Functional Theory (DFT) Investigation of Vibronic-Mode Coupling Structure in Vibrational Spectra Analysis", Glob Imaging Insights 4 (2), 1-14, 2019

430. Heidari, J Esposito, Caissutti, "Time-Resolved Resonance FT-IR and Raman Spectroscopy and Density Functional Theory Investigation of Vibronic-Mode Coupling Structure in Vibrational Spectra of Nanopolypeptide Macromolecule beyond the Multi-Dimensional Franck-Condon Integrals Approximation and Density Matrix Method", Glob Imaging Insights 4 (2), 1-14, 2019

431. Heidari, J Esposito, Caissutti, "Cholera Toxin Time-Resolved Absorption and Resonance FT-IR and Raman Biospectroscopy and Density Functional Theory (DFT) Investigation of Vibronic-Mode Coupling Structure in Vibrational Spectra Analysis", Glob Imaging Insights 4 (2), 1-14, 2019

432. Heidari, J Esposito, Caissutti, "Nodularin Time-Resolved Absorption and Resonance FT-IR and Raman Biospectroscopy and Density Functional Theory (DFT) Investigation of Vibronic-Mode Coupling Structure in Vibrational Spectra Analysis", Glob Imaging Insights 4 (2), 1-14, 2019

433. Heidari, J Esposito, Caissutti, "Cangitoxin Time-Resolved Absorption and Resonance FT-IR and Raman Biospectroscopy and Density Functional Theory (DFT) Investigation of Vibronic-Mode Coupling Structure in Vibrational Spectra Analysis", Glob Imaging Insights 4 (2), 1-13, 2019
434. Heidari, J Esposito, Caissutti, "Ciguatoxin Time-Resolved Absorption and Resonance FT-IR and Raman Biospectroscopy and Density Functional Theory (DFT) Investigation of Vibronic-Mode Coupling Structure in Vibrational Spectra Analysis", Glob Imaging Insights 4 (2), 1-14, 2019

435. Heidari, J Esposito, Caissutti, "Brevetoxin (a) and (b) Time-Resolved Absorption and Resonance FT-IR and Raman Biospectroscopy and Density Functional Theory (DFT) Investigation of Vibronic-Mode Coupling Structure in Vibrational Spectra Analysis: A Spectroscopic Study on an Anti-HIV Drug”, Cientific Drug Delivery Research 1 (2), 11-16, 2019

436. Heidari, J Esposito, Caissutti, "Cobrotoxin Time-Resolved Absorption and Resonance FT-IR and Raman Biospectroscopy and Density Functional Theory (DFT) Investigation of Vibronic-Mode Coupling Structure in Vibrational Spectra Analysis", Trends in Res 3 (1), 1-13, 2019

437. Heidari, J Esposito, Caissutti, "Cylindrospermopsin Time-Resolved Absorption and Resonance FT-IR and Raman Biospectroscopy and Density Functional Theory (DFT) Investigation of Vibronic-Mode Coupling Structure in Vibrational Spectra Analysis", Trends in Res 3 (1), 1-14, 2019

438. Heidari, J Esposito, Caissutti, "Anthrax Toxin Time-Resolved Absorption and Resonance FT-IR and Raman Biospectroscopy and Density Functional Theory (DFT) Investigation of Vibronic-Mode Coupling Structure in Vibrational Spectra Analysis", Trends in Res 3 (1), 1-14, 2019

439. Heidari, K Schmitt, M Henderson, E Besana, "Investigation of Moscovium Nanoparticles as Anti-Cancer Nano Drugs for Human Cancer Cells, Tissues and Tumors Treatment”, Elixir Appl Chem 137A, 53943-53963, 2019

440. Heidari, K Schmitt, M Henderson, E Besana, "Study of Function of the Beam Energy and Holmium Nanoparticles Using 3D Finite Element Method (FEM) as an Optothermal Human Cancer Cells, Tissues and Tumors Treatment", European Journal of Advances in Engineering and Technology, 6 (12): 34-62, 2019

441. Heidari, K Schmitt, M Henderson, E Besana, "Human Cancer Cells, Tissues and Tumors Treatment Using Dysprosium Nanoparticles", Asian J Mat Chem 4 (3-4), pp 47-51, 2019

442. Heidari, K Schmitt, M Henderson, E Besana, "Simulation of Interaction of Synchrotron Radiation Emission as a Function of the Beam Energy and Plutonium Nanoparticles Using 3D Finite Element Method (FEM) as an Optothermal Human Cancer Cells, Tissues and Tumors Treatment", J Cancer Research and Cellular Therapeutics, Volume 2 (4), Pages 1-19, 2019.

Copyright: $(2020$ Heidari A. This is an open-access article distributed under the terms of the Creative Commons Attribution License, which permits unrestricted use, distribution, and reproduction in any medium, provided the original author and source are credited. 